IZA DP No. 7982

Immigrants and Demography:

Marriage, Divorce, and Fertility

Alícia Adserà

Ana Ferrer

February 2014

Forschungsinstitut

zur Zukunft der Arbeit

Institute for the Study

of Labor 


\title{
Immigrants and Demography: Marriage, Divorce, and Fertility
}

\author{
Alícia Adserà \\ Princeton University, \\ CREAM and IZA \\ Ana Ferrer \\ University of Waterloo \\ and CLSRN
}

\section{Discussion Paper No. 7982 \\ February 2014}

\author{
IZA \\ P.O. Box 7240 \\ 53072 Bonn \\ Germany \\ Phone: +49-228-3894-0 \\ Fax: +49-228-3894-180 \\ E-mail: iza@iza.org
}

Any opinions expressed here are those of the author(s) and not those of IZA. Research published in this series may include views on policy, but the institute itself takes no institutional policy positions. The IZA research network is committed to the IZA Guiding Principles of Research Integrity.

The Institute for the Study of Labor (IZA) in Bonn is a local and virtual international research center and a place of communication between science, politics and business. IZA is an independent nonprofit organization supported by Deutsche Post Foundation. The center is associated with the University of Bonn and offers a stimulating research environment through its international network, workshops and conferences, data service, project support, research visits and doctoral program. IZA engages in (i) original and internationally competitive research in all fields of labor economics, (ii) development of policy concepts, and (iii) dissemination of research results and concepts to the interested public.

IZA Discussion Papers often represent preliminary work and are circulated to encourage discussion. Citation of such a paper should account for its provisional character. A revised version may be available directly from the author. 
IZA Discussion Paper No. 7982

February 2014

\section{ABSTRACT}

\section{Immigrants and Demography: Marriage, Divorce, and Fertility}

This is a draft chapter for B. R. Chiswick and P. W. Miller (eds.) Handbook on the Economics of International Migration. It discusses some of the data and methodological challenges to estimating trends in family formation and union dissolution as well as fertility among immigrants, and examines the evidence collected from the main studies in the area. The literature on immigrant family formation is diverse but perhaps the key findings highlighted in this chapter are that outcomes depend greatly on the age at migration and on the cultural norms immigrants bring with them and their distance to those of the host country. With regard to marriage we focus on the determinants of intermarriage, the stability of these unions, and the timing of union formation. The last section of the chapter reviews, among other things, a set of mechanisms that may explain the fertility behavior of first generation immigrants; namely, selection, disruption and adaptation. The section ends with a focus on the second generation.

JEL Classification: J11, J12, J13, J15

Keywords: $\quad$ age at migration, immigrant intermarriage, union dissolution, immigrant fertility, fertility disruption, adaptation, second generation, culture

Corresponding author:

Alícia Adserà

Woodrow Wilson School of Public and International Affairs

Princeton University

347 Wallace Hall

Princeton NJ 08544

USA

E-mail: adsera@princeton.edu 


\section{Motivation: Why study immigrant marriage and fertility?}

In recent years, developed countries have seen the number and diversity of their foreign born populations increase at a rapid pace. As shown in Table 1, foreign-born individuals represented by 2010 over 10 percent of the population in the major receiving developed countries and this share stood at over twenty percent for Australia and Canada. With many of these countries facing increasing old age-dependency ratios and demographic pressures on social services, particularly as baby- boomers retire, the contribution that immigrants can make to the sustainability of population levels and the current structure of welfare states has attracted the interest of both academics and policymakers (U.N. 2001, Coleman 2006; Sobotka 2008). More importantly, immigrants' social outcomes such as their rates of household formation and fertility are ultimately markers of the extent of their assimilation (or adaptation) to the country of reception. In addition, these outcomes impact the role of migrant women in the labor market and the investments made in their children. Motivated by these concerns, a substantial body of research has developed to examine family formation and fertility among immigrants and their children, and the extent to which the fertility of migrant populations differs from or converges to that of the native born population.

The speed at which this adaptation occurs both in terms of fertility and intermarriage, among other outcomes, has been found to hinge on immigrant characteristics, such as age (or birth cohort), age at migration, education or cultural proximity to the host country (such as social attitudes toward contraceptive measures, gender preferences, and out of wedlock childbearing, among many others). In particular, cultural proximity seems to ultimately influence the perception of constraints shaping family formation and hence the integration process. ${ }^{1}$ As a result, the variety of cultural backgrounds that immigrants bring with them introduces an extraordinary heterogeneity in empirical analyses that many studies reviewed in this chapter exploit. Finally, the cultural distance between host and sending country and immigration policies at destination will likely influence the perception of constraints and the integration process of immigrants.

A large majority of the studies of family formation reviewed in this chapter aim at

\footnotetext{
${ }^{1}$ Given the relative infrequency of these decisions, some researchers argue that acculturation is likely to be a long term process and complete assimilation may only be reached after several generations (Fernandez and Fogli, 2009).
} 
measuring the extent of migrant integration in their countries of reception by comparing their patterns of behavior with those of the native born in outcomes such as the number of children and the timing of childbearing, or the age and prevalence of marriage, among others. Decreases in the immigrant-native differentials are viewed as evidence of a reduction in the influence of the norms of the country of origin and adaptation (or acculturation) to their new environment. The degree of adaptation is also defined by the convergence of immigrants' preferences (in issues such as the desired number or gender of children) to those of natives or by immigrants’ propensity to intermarry with native-born.

In particular, as it will become clear when we survey the literature on union formation in section 3, research on the prevalence and determinants of intermarriage is the focus of most of those papers. This is not surprising given the large and increasing numbers of mixed marriages in the main destination countries. The last two columns in Table 1 present the share of native born individuals married to immigrants, among those married, and also the share of married immigrants whose spouse is a native-born. In Europe around 5 to 7 percent of natives have formed a mixed marriage and among foreign-born, not surprisingly, the proportion that has intermarried is larger and stands between a minimum of 17 per cent in Greece and over one third in France, the Netherlands, Belgium and Sweden. In the US numbers stand at 4.4 percent for natives and 27.9 percent for foreign born. In Australia around 31 percent of all marriages include both a native and a foreign-born. In addition to understanding the process of formation of those unions, the literature analyzes their stability and whether their prevalence is similar among individuals of different source countries.

(Table 1 Here)

The large immigrant flows to developed countries, particularly to European countries, portrayed in Table 1 have also caught the attention of researchers for their potential impact on childbearing trends in countries where fertility was at or below replacement levels (around the 2.1 children per women needed to sustain the population at a constant level). To highlight the growing relevance of births to immigrants in major European destinations, the first two columns in Table 2 present the shares of total births from either immigrant women, in the first column, or foreign nationals, in the second column. The data comes from Sobotka (2008) who compiles it 
from different sources, as indicated in the table, to show the growing share of children born to foreign-born mothers across European countries. ${ }^{2}$ In the majority of countries the shares are well above 10 per cent and in some cases above 15 percent of new births. Of course, since immigrant women are likely to arrive at childbearing ages, their shares of births are not surprisingly larger than their own share in the total of the population. In addition, if a large share of these migrant women arrives from relatively high fertility countries, they may bring with them norms from their countries of birth regarding fertility that exceed the local expectations. The next two columns in Table 2 present the total fertility rates (TFR) for natives (or native nationals) and for immigrants (or foreign nationals) across Europe. The immigrant-native gaps are noticeably large in most countries. However, Sobotka (2008) shows in his paper that, given their share in the overall population, the net effect of these migrants coming from high fertility countries is still relatively small on the period total fertility of most reception countries, ranging between 0.05 and 0.10 increases of the TFR in absolute terms. Moreover, a substantial fraction of papers reviewed in section 4 show a remarkable either partial or full convergence of the fertility of immigrants, and second generation individuals, to the levels of native born in many of the countries analyzed.

(Table 2 here)

In section 2 we highlight some important methodological challenges that concern all the literature reviewed in this chapter. Section 3 focuses on union formation and dissolution and section 4 surveys the mechanisms that drive immigrant fertility in reception countries. We close the chapter with a general overview of findings.

\section{Methodological Challenges to the study of Immigrant Marriage and Fertility}

Researchers studying immigrant household formation and fertility face two important methodological problems: first, the fact that the sample of immigrants observed in the destination country is a selected group from the country of origin; and second, the lack of good datasets to appropriately answer some of the common research questions on the field.

\footnotetext{
${ }^{2}$ Finding homogenous and comparable measures of births to immigrants both across time and across countries is a difficult task. The definitions of immigrants used by researches and official statistics vary widely, particularly when it comes to looking at citizenship.
} 


\subsection{Immigrant Selection and Individual Heterogeneity}

When researchers interpret convergence in immigrant family formation patterns to those of reception countries strictly as evidence of adaptation or integration, they may rely on the assumption that immigrants are a random sample of the population of origin. However, some immigration analyses often overlook the process of immigrant selection in the source country, which is likely to influence immigrant family formation and fertility. When ignoring likely dissimilarities between the behavior of the non-immigrant and the immigrant populations in the country of origin, differences in observed outcomes or characteristics between immigrants and natives are attributed to the culture of origin or, alternatively, to the process of migration itself (for example, its impact on delaying or accelerating marriage or childbearing), while they may primarily reflect distinctive characteristics of the immigrant population. If immigrant women, for example, are more driven to economic activity than their non-migrant compatriots, we could observe relatively low rates of partnership formation or low fertility in the host country, not because of "assimilation" to norms in destination countries but because of the immigrants' own attitude towards work.

The fact that immigrants are not a random sample of the population of origin has long been incorporated into theoretical models of immigration (Borjas 1987, 1991, 1999). However, accounting for this fact in empirical models is complicated because the degree of selectivity varies substantially depending on the country of origin and timing of migration and it is sometimes influenced by non-observable characteristics such as ambition or motivation (Feliciano, 2005). This implies that proper handling the immigrant selection issue calls for large enough samples of immigrants in the destination country to enable the researcher to account for differences in cultural background, religion, or timing of entry, among other things. Alternatively (or better, additionally), addressing selection adequately may require large amounts of information on the population in the country of origin. Unfortunately both types of data may not be readily available in most cases.

In addition, studies on family formation have to deal with problems of endogeneity: family formation decisions are so intertwined with educational and labor market choices that it may be unrealistic to regard them as exogenous to one another. Hence, individual heterogeneity is likely to drive the association between things such as education and family formation or 
fertility. Individuals with a strong focus on their careers may also have low preferences for committed partnerships and/or fertility, and this introduces (a different type of) selection bias in the analysis. We may then observe high levels of labor force participation together with low prevalence of marriage and low numbers of children. The direction of the bias is not straightforward. For instance, if children are normal goods, one would expect the effect of income on fertility to be positive, and individuals with more income to have more children since they can afford to pay for the additional services involved in raising them. However, this effect could be underestimated whenever some families have higher incomes precisely because they have postponed or reduced fertility and are exerting more effort in the labor market. Similarly, the effect of education on marriage and fertility can be overestimated if individuals with low preferences for education are more likely to marry early and form families. Again, fully accounting for joint labor market, education and family formation decisions requires highly specialised data that it is not typically available to researchers. As a result, few studies can provide causal effects for estimates of intermarriage or immigrant fertility adaptation, among other topics.

A few papers exploit relatively exogenous variations that attenuate some of these biases. For instance, some researchers focus on the behavior of migrant children (those who arrived to the reception country before adulthood), for whom the link between migration decisions and subsequent behavior is more tenuous. Their findings shed more light on integration because individuals in their samples are not so affected by selection into migration as the general migrant population (Bleakly and Chin, 2010; Adserà, et Al. 2012; Adserà and Ferrer, 2013a; Beck, Corak and Tienda 2012). Similarly, others have employed information of countries of ancestry, to understand the behavior of second-generation of individuals who were not born on those countries (Fernandez and Fogli 2006).

Addressing the restrictions that these types of selection issues impose on the data has forced researchers to look for alternative sources of information. In general we identify three main approaches in the literature surveyed in this chapter. A first common shortcut is to proxy for immigrant selection using broad measures (in general aggregate at the country level) such as country of origin gross domestic product or income inequality (Borjas 1987; Cobb-Clark 1993), distance to the host country (Jasso and Rosenzweig 1990), pre-migration occupational status (at individual level if available) (Lobo and Salvo 1998b) or education 
(Rumbaut 1997, Feliciano, 2005). A second alternative involves the use of individual panel (longitudinal) data that might help to remove some of the unobserved heterogeneity leading to selection bias through the inclusion of individual fixed-effects. However, the high cost involved in collecting panel data information typically means a reduction in sample size or information detail in those types of datasets compared to repeated cross-sections. This greatly handicaps immigration studies, which, as mentioned, require large samples of immigrants. Some widely used longitudinal surveys by migration researchers, such as the German SocioEconomic Panel (G-SOEP), have resorted to oversampling migrant populations. As a third alternative, in the absence of long panel data with sufficiently large samples of immigrants, researchers prefer the use of synthetic cohorts of immigrants from pooled cross section surveys, such as the census. This methodology introduced by Borjas (1985) allows researchers to follow groups of immigrants with similar characteristics across time, thereby eliminating some of the cohort, rather than individual, heterogenenity. ${ }^{3}$

\subsection{Data Limitations to Measuring Family Formation}

Research into family dynamics among immigrants is hindered by the lack of nationally representative data with detailed enough information on important dimensions such as the context of migration (i.e. type of entry visa, national origins, generation status, age at migration, linguistic origins), the migration and assimilation processes (i.e., timing and order of migration among spouses, the presence of children, parents or connections to family members in sending areas or in countries of reception), along with detailed measures of family interactions (i.e., fertility intentions of both spouses, complete fertility and marriage histories) or pre-migration information (i.e., labor force participation, years of schooling or family structure prior to migration).

Incomplete information on fertility and marriage histories may lead researchers to associate the observed behavior of migrants to convergence of marital and fertility propensities to those of the native born, because of their inability to control for past events (such as previous unions, or children left behind in the country of origin) that affect current

\footnotetext{
${ }^{3}$ This methodology has been broadly applied to the study of immigrant labour markets (Chiswick, 1978; Ferrer and Riddell 2008; Clark and Lindley 2009).
} 
propensities. The number of children an immigrant may choose to have in the host country, for example, will depend on the number (and plausibly the gender) of children they had previous to migration, which might be unknown or underestimated if some children did not move with their parents. Lack of detail in the age at arrival is another good example where data limitations restrict the ability to properly test some theoretical models or understand whether some mechanisms put forward by researcher to explain demographic behavior are at work. Even though many datasets lack complete information on age at arrival, others, typically publicly accessible census data, provide five year intervals. Some models reviewed later in the chapter are concerned with testing whether there are discontinuities in some socioeconomic outcomes for specific ages of arrival (particularly during childhood) and in those cases obtaining the exact year of migration is of essence.

The most common sources of data for the studies reviewed here are the census or related surveys, such as the Labour Force Survey (Canada, UK) or the Current Population Survey (US). The main advantage of these data sets lies in affording large samples of all immigrant groups, which allows detailed examination of racial and ethnic patterns of marriage and fertility. However, their lack of detailed family or union formation histories typically confines the analysis that researchers can conduct with these data sources in important ways that introduce selection bias in the estimates. A good example of those limitations is found in most studies of marriage that employ census data. They are confined to currently married couples, as the census typically lacks marital histories. This is prone to bias the observed sample towards endogamous marriages which have higher stability and the most recently married which still have not had time to dissolve (Jacobs and Furstenberg, 1986). One common approach to minimizing potential selection biases is to restrict the sample to younger couples, more likely to be in first marriages.

Cohabitation or any other mode of informal union is particularly difficult to trace because in many surveys it is not specifically reported or counted as such. This is clearly the case for census data, but it can be also a difficulty in otherwise rich datasets such as some population registrars in Europe. Researchers have to make assumptions about not-related individuals living in the same household for a certain period of time to decide whether they can plausibly be classified as cohabitants. In addition, lack of proper measures of these informal unions maybe particularly relevant when studying immigrants since the experience 
and meaning of cohabitation varies considerably across origin countries. This is one instance in which having information about country of origin becomes important as consensual unions may be very similar to marriage for immigrants from countries with a long tradition in cohabitation. ${ }^{4}$

Another case in which the tradeoffs involved in the use of census data become apparent relates to the use of the own-children-method to measure individual fertility. Census data typically reports the number of children living in the household rather than the number of children born. The own-children-method exploits the fact that the vast majority of young children live with their mother at the time of the census to reconstruct women fertility histories by linking children and mothers living in the same household (Cho, 1973). ${ }^{5}$ This estimation strategy presents some challenges when applied to studying the fertility of immigrants (Dubuc 2009). First, some children may not live with their mothers, because they were left behind in the country of origin under the care of relatives. Second, it may be difficult to properly capture the early childbearing of older women as some of their children may have already left home. To the extent that these effects are important, the own children method will underreport fertility and introduce error in the measurement of the dependent variable. This should be of particular concern if the miss-measurement occurs at different rates for immigrant and the native born; for instance if departure of children from the household in their late teens or early adulthood is far more common among the native-born population than among migrants (or vice versa) (Adserà and Ferrer, 2013a)

There are other challenges to measuring fertility. An important one concerns the choice of the proper aggregate fertility measure to describe the fertility trends in the country. A broadly used measure of fertility is the total fertility rate (TFR), which is a hypothetical measure estimating the number of children a woman would have if she were to give birth according to the prevailing age-specific fertility rates (ASFR). ${ }^{6}$ This is the measure displayed

\footnotetext{
${ }^{4}$ This is the case with cohabitation in some Latin American countries (Qian, Glick and Batson, 2012; Castro Martin, 2002).

${ }^{5}$ For Canada, Belanger and Gilbert (2003) show that estimated fertility differentials for immigrants and domestic born individuals for the period 1996-2001 using both methods are not very sizeable - with a downward bias of the census for women younger than 30 and an upward bias for those aged beyond 30 .

${ }^{6}$ ASFRs are obtained by dividing the number of births to women of a given age range (typically 5 years) by the total population of women of that age that year. The TFR is constructed by aggregating ASFRs.
} 
in Table 2. An actual measure of the fertility experience of women is the completed fertility rate (CFR), which measures the average number of births that women of a given birth cohort actually have over the reproductive lives. While CFR has the advantage of truly reflecting fertility patterns, it does not reflect current fertility behavior and it needs to collect all the data for a particular cohort until the end of their fertile years to come up with a final estimate. The current fertility patterns are better captured by TFR, which in turn has the disadvantage of being a composite measure that may confound changes in the timing of births (tempo effect) with changes in the quantity of births. Thus, TFR can be accurate estimate of CFR only when both the timing and quantum of births are not changing much across generations. Hence during periods in which the timing of births accelerates and concentrates in the first part of the fertile years, the TFR overestimates the CFR. This is an important consideration as TFRs are typically used to predict population growth and to calculate the demand for public services. When calculating the TFR for immigrant populations, further consideration have to be taken into account. For instance, the age and marital composition of immigrant groups and the disruption effects of migration on fertility all play a role in increasing the volatility of TFRs, leading to even higher distortions in predicted population growth for immigrant groups (Parrado, 2011).

Finally, before opening the discussion of the two central themes of the chapter, it is important to note that comparisons between immigration studies are not straightforward. Different studies use unique samples, diverse definitions of intermarriage and measures of fertility, and include varying sets of control variables. For instance, although the term immigrant commonly designates the foreign born, in some cases nationality determines immigrant status in some datasets. This problem was already highlighted when discussing Table 2 where some studies measure the fertility of the foreign born and other that of the foreign nationals. Further studies may use different definitions of ancestry to define an endogamous marriage. In some cases they are defined on nativity (whether foreign or native born) and in others they also incorporate race/ethnicity to the measure. Finally limited availability of fertility histories might impose the need to use fertility measures based on the "own child method" rather than on actual births. Despite the different samples and variable definitions employed, several findings appear very robust across the studies in each topic, and we focus on them. 


\section{Marriage and divorce among immigrants}

Family formation has been one of the more prolific areas of research in immigration. ${ }^{7}$ Marriage propensities are part of a country's cultural background and hence potentially indicative of cultural differences between the immigrant and native-born population. Further, the capacity to form and maintain exogamous unions (between a foreign and a native born) can be interpreted as the quintessence of successful integration. Duncan and Trejo (2007) research reveals that selectivity into intermarriage influences ethnic identification, which on itself has important consequences to measure the intergenerational integration of those with immigrant ancestry. Hence, it is not surprising that most studies in this area focus on intermarriage, with marriage propensities receiving only passing attention. Similarly, union dissolution among immigrants has been the object of great interest both among researchers and policymakers because of the special vulnerability of children and women in immigrant families, who could be less established in the labor force and more at risk of poverty than men, who are traditionally the bread winner in those families (Qian 2013).

We have summarized the main features of the samples and methods used in the most relevant papers in the marriage literature in Table 3 to guide the reader throughout the diversity of results reviewed in this section of the chapter.

\subsection{Microeconomic Models of Marriage Formation}

The development of the modern economics of the family has its roots in Becker's work. ${ }^{8}$ His path-breaking model of household formation underlies current theories of marriage, divorce, fertility and intra-family division of labor. The basic marriage model outlined in Becker's 1974 seminal paper A Theory of Marriage, assumes that individuals weight the potential contribution of likely partners to household produced goods (companionship, children, quality of meals, among others) to determine the gains of marriage over remaining single. Both options should equal each other in equilibrium. This conceptualization gives rise to a market relationship between the output received in the marriage market and the number

\footnotetext{
${ }^{7}$ Through the chapter we use marriage to refer indistinctly to any form of formal unions, including common law, because these are usually undistinguishable.

${ }^{8}$ The economics of the family emerged as a distinct field with the publication of Schultz's volume in 1974.
} 
of participants in that given market. In a competitive equilibrium (as assumed by Becker), couples are formed in a manner which maximizes aggregate surplus in the marriage market. ${ }^{9}$ Hence, the model predicts how changes in the relative availability of men and women might affect the distribution of marriages. The model also has implications in terms of sorting: individuals with similarities in traits that are complementary to each other will tend to marry (positive assortative matching), whereas individuals with differences in traits that are substitutes will also tend to marry (negative assortative matching). For instance, individuals of similar religious preferences will likely share preferences regarding the manner of rising their children, and this, in turn, will enhance their gains from marriage. Similarly, two potential partners with comparative advantage in the labor market and in household production respectively (and hence different expected market wages) will benefit from increased household production through division of labor.

The scant empirical support for Becker's prediction of negative assortative matching (on observed wages) prompted Lam's (1988) model of marriage, which extends Becker's framework to include a public good produced within the household. Since many of the commodities produced within families are also jointly consumed within families, it is optimal for marriages to form between people with similar demands for these goods.

Keely (1977) formulates Becker's model of marriage as a search model, where potential spouses have incentives to seek "suitable" mates. Suitability in this model is measured by a "marital wage" which is not observed, but that can be proxied by a marital offer. In a world with search costs, optimal matches do not always occur, forcing marriage market participants to make decisions about the characteristics of spouses they value most. One of the largest and most common search costs involves the spatial distribution of potential partners, which tends to make marriage markets local. As discussed below, the definition of what constitutes a marriage market is central to the empirical analysis of multi-ethnic marriages. Chiswick and Lehrer (1991) and Lehrer (1998) similarly model intermarriage using a search model where, in equilibrium, the marginal cost of finding a more suitable partner equals its marginal benefits.

\footnotetext{
${ }^{9}$ Alternatively, one can assume that gains from marriage are the result of a bargaining process between spouses (Lundberg and Pollack, 1993).
} 


\subsection{The Determinants of Intermarriage}

The marriage models discussed above have distinct implications for marriage markets with significant ethnic diversity. Since similar ethnic background are likely to be complements in the production of ethnicity-related household public goods (such as compliance with ethnic celebrations, or types of food), these models predict positive assortative matching based on ethnic background. The empirical study of racial intermarriage has a long tradition in the US (Bratter and King, 2008; Shoen and Wooldrege, 1989; Sandefur and McKinnell, 1986), where it was perceived as a measure of the persistence of racial (particularly blackwhite) divisions. With the increase in migrant population flows towards Western economies, the intermarriage among immigrants has taken center-stage as a separate case to consider. The intermarriage models in this specific case imply that immigrants are more likely to marry other immigrants, preferably those of the same ethnic or religious background. In a study on the causes of exogamous marriages, Kalmijn (1998) groups the determinants of partner choice in the following three categories: (1) individuals' preferences for certain characteristics in a spouse, (2) influence of the social group of which they are members and, (3) the potential constraints imposed by the structure of the marriage market where they are searching for a spouse.

Applying these categories to the study of homogamy among immigrants, a model of intermarriage could be estimated by the following stylized equation:

$$
M_{i k j}=X^{\prime}{ }_{i k j} \beta_{0}+\operatorname{Assim}_{i k j} \beta_{1}+M M k t^{\prime}{ }_{k j} \beta_{2}+e^{\prime}{ }_{i k j}
$$

where $M_{i k j}$ is an indicator of endogamous marriage for individual $i$ of ethnicity $k$ in marriage market $j$. The independent variables include a vector of individual socioeconomic characteristics, denoted $X_{i k j}$, a vector of indicators measuring immigrant assimilation $\left(\right.$ Assim $\left._{i k j}\right)$, such as immigrant generational status, age at immigration or language skills, and a vector including the characteristics of the individual's marriage market $\left(M M k t_{k j}\right)$, such as the probability of meeting a potential partner of the same ethnicity within the marriage market, or the sex-ratio in the individual's own marriage market. ${ }^{10}$ The odds ratio of an endogamous

\footnotetext{
${ }^{10}$ Sex ratios, defined as the ratio of male to female individuals within the group/area considered, account for spousal competition in the marriage market. A predominance of men, other things equal, will increase exogamous marriages for men and reduce it for women.
} 
marriage as specified in equation 1 is typically estimated with linear probability or logit models. ${ }^{11}$ Alternatively, the use of loglinear models is not unusual within the sociology literature studying ethnic intermarriage (Qian and Lichter, 2007; Rosenfeld, 2002). ${ }^{12}$

The hypothesis of assortative matching (across immigrant or nativity status) predicts lower rates of endogamous marriage among assimilated immigrants - such as child immigrants who migrated before adulthood or the children of immigrants. ${ }^{13}$ Since preferences for partners are more likely to conform to the environment where the individual grew up, the younger the immigrant arrived and the looser the ties to the home country, the more likely he or she intermarries. Hence, the estimated coefficients for the parameters in $\beta_{1}$ associated to assimilation, driven by the hypothesis of assortative matching are expected to be negative.

The structure of the marriage market (summarized in the term $M M k t_{i k j}$ ), on the other hand, accounts for the constraints to individuals' preferences resulting from the size of their own group and the gender imbalances within groups. The smaller the group size and the higher the sex imbalance, the higher the predicted rates of intermarriage. ${ }^{14}$ Researchers' definitions of appropriate marriage markets are strongly determined by data availability. Among others, Furtado (2012), Furtado and Theodoropoulos (2011), Kalmijn and Van Tubergen, (2010), and Chiswick and Houseworth (2011) discuss the effect of gender imbalances within ethnic groups on intermarriage propensities among immigrants to the US, but each analysis uses a slightly different definition of the relevant marriage market. We have summarized the sample characteristics and the main control variables included in the analysis in Table 3.

(Table 3 here or somewhere in the middle of Section 3)

\footnotetext{
${ }^{11}$ The model calculates the odds of endogamous marriages out of the total population married. Alternatively, a model with three marital states (endogamous, exogamous to a native born or exogamous to an immigrant from other ethnicity) could be estimated using a multinomial logit model.

${ }^{12}$ Loglinear models are more accurate in that they take the marriage, rather than the individual as the unit of analysis, but are less flexible in accommodating continuous variables which are important in understanding the determinants of intermarriage among immigrants.

13 A recent series of studies assessing the cultural integration of European immigrants (Algan et al. 2012) confirms the idea that endogamous marriage is more prevalent among first generation immigrants, but less prevalent among the second generation, than the among the third.

${ }^{14}$ See Niedomysl, Östh and van Ham (2010) for an exploration on the globalization of marriage
} 
Overall, there is strong empirical support for both the "assimilation the marriage market "structuralist" determinants of mixed married among immigrant discussed above. Recent immigrants and those arriving at older ages are more likely to form endogamous marriages than those who migrate as young children or have already lived in the country for some time because their cultural barriers with the host population are greater. Similarly, softer ties to ancestry increase the likelihood of mixed marriage among the children of immigrants relative to that of the foreign born. Adherence to religion (and religiosity) and increased probability of contact with co-ethnics among more recent arrivals are all significant predictors of endogamous marriages. Several papers that examine the determinants of intermarriage for different ethnic groups and across generation levels (Dribe and Lundh, 2011; Kalmijn and van Tubergen 2010; van Tubergen and Maas, 2007; Gonzalez-Ferrrer, 2006; Lievens, 1998) find consistent evidence for the assimilationist approach. ${ }^{15}$ In this regard, the most comprehensive review of the assimilationist determinants of immigrant marriage is found in Chiswick and Houseworth (2011) whose analysis includes years in the USA, age at arrival, age at first marriage, and linguistic distance from English. After controlling for a wide range of marriage market and individual characteristics, they find that the probability of intermarriage is higher for younger, more educated immigrants whose linguistic distance is closer to English.

With regard to marriage market characteristics, most studies find that it is important to control for marriage market effects, particularly size of the ethnic group, and that these variables usually have the expected sign (Chiswick and Houseworth, 2011; Furtado and Thodoropolous, 2011; Dribe and Lundh, 2011, van Tubergen and Maas, 2007; Nielsen et al. 2006). However, the evidence on gender imbalance within ethnic group as a positive determinant of exogamous marriages is more mixed. Some studies do not find significant positive associations between sex ratios and endogamous marriages (Kalmijn and Van Tubergen 2010).

In North America, the analysis of the marriage determinants of particular ethnicities has been greatly dominated by a focus on the marriage patterns of Hispanics and Asians, which constitute the majority of recent immigrants. Data from the American Community Survey 2008 indicates that among "newlyweds" (those who married in the 12 months previous to the

\footnotetext{
${ }^{15}$ See Furtado and Trejo (2013) for an excellent survey of this literature.
} 
survey), 39.4 of native born Hispanics and 11.7 foreign born Hispanics where married to a spouse of a different race/ethnicity. The same percentages among Asians stood at 46.0 and 25.9 respectively (Passel et al. 2010). In many studies and official statistics, particularly those employing US and Canadian data, nativity (place of birth) and race/ethnicity are often intertwined and it becomes difficult to separate those categories to examine them separately. ${ }^{16}$ Qian et al. (2012) is a good example of this strand of work. The paper studies the spousal or partner racial/ethnic background among married or cohabiting individuals aged 20-34 in the US 2000 census and it differentiates among U.S.-born and migrants (by age at arrival). Table 4 provides some data from this paper on the distribution of partners among major migrant groups (Chinese, Filipino and Mexican) depending on whether they are coethnic (from the same ethnicity), Interethnic (other Asian or Hispanic), white or a member of other racial minority groups. Some stylized facts that accord to the theories just described are apparent in Table 4. Among groups, coethnicity is positively associated with the size of the ethnic group in the US; with Mexicans being the largest of all. Second, the likelihood of intermarriage (or cohabitation outside the ethnic group) decreases monotonically with age at arrival and it is the highest among those born in the U.S.

To keep the focus of the chapter, below we restrict our attention only to those studies that explicitly consider the role of immigration (nativity), even if it is combined with race/ethnicity, in the analysis. Liang and Ito (1999) offer a descriptive study of the intermarriage patterns of the population of Asian ancestry in the New York city district that are consistent with those found in subsequent studies. Rosenfeld (2002) studies the intermarriage patterns of individuals of Mexican descent in the US. More recently Lee and Boyd (2008) compare intermarriage among individuals of Asian ancestry in US and Canada identifying similar roles for different determinants of intermarriage in the two countries. They find a higher intermarriage probability of Asian women, relative to Asian men in both countries, and higher overall intermarriage probability in the US.

(Table 4 here)

\footnotetext{
${ }^{16}$ Canadian statistics, for example, often report the rate of intermarriage among visible minorities (defined as persons, other than Aboriginal peoples, who are non-Caucasian in race or non-white in color). Data from the 2006 Canadian census indicated that 55.6 per cent of native-born visible minorities and 12.1 per cent of foreign born visible minorities where in mixed unions (Milan et al. 2010).
} 
Finally, an important dimension to consider in the analysis of endogamous marriage is generational status. It is commonly believed that a desire to assimilate in the host country should lead immigrants to marry similarly (or more) integrated immigrants within the same generational status, rather than recently arrived immigrants (Pagnini and Morgan, 1990). This would be observed in the data particularly if no new large waves of co-ethnic immigrants are expected to arrive in the host country in the coming years. However in some cases, strong preferences for co-ethnic marriages and thin local marriage markets might also give rise to the practice of importing partners from the country of origin. This phenomenon may appear in the data as favouring ethnic homogamous marriages to recent immigrants, while in fact those partners are, as the literature traditionally labels them, imported brides (since the majority of them tend to be women). This practice seems to prevail among some Turkish and Moroccan minorities in Western Europe (Lievens, 1999). Gonzalez-Ferrer (2006) also finds an association between low education and importing a partner among immigrant men to Germany, but not among women. ${ }^{17}$

\subsection{Intermarriage as Assimilation}

The empirical literature has tried to determine to what extent intermarriage is an indicator or a cause of assimilation. ${ }^{18}$ It is true that intermarried immigrants in Australia, France, the US and Canada have more schooling and earn significantly more than immigrants marrying other immigrants, even after controlling for human capital endowments unrelated to marriage (Meng and Meurs, 2006; Meng and Gregory, 2005; Kantarevick (2004; Qian and Litcher, 2001, 2007; Baker and Benjamin, 1997; Worswick, 1996). There are two possible explanations for this stylized fact. One is that the relationship is spurious, driven by unobserved abilities or preferences of individuals who marry outside their ethnic group. The second option is that the relationship is causal because marrying a native-born spouse speeds up assimilation of the immigrant partner (or alternatively, marrying endogamously reduces assimilation opportunities for immigrants).

\footnotetext{
${ }^{17}$ Lievens (1999) proposes the hypothesis that women immigrants might import partners to achieve modern goals. Gonzalez-Ferrer (2006), Hooghiemstra (2001) and Celikaksoy et al. (2003), however, find no support for this hypothesis.

${ }^{18}$ In the extreme, selective intermarriage may influence ethnic identification. This may dilute assimilation outcomes if some assimilated individuals no longer identify with the original ethnic category (Duncan and Trejo, 2007).
} 
A model to estimate such effect follows quite easily from equation (1). In addition to modelling the odds of intermarriage, researchers introduce a second equation with an outcome $y$ (either education or wages) specified as a function of different assimilation variables, such as years since migration or English ability (Assim), a vector of sociodemographic characteristics, including human capital variables, $(X)$, and an indicator for endogamous marriage $\left(M_{1}\right)$ :

$$
\begin{gathered}
y_{i j}=X_{i j}^{\prime} \beta_{0}+\operatorname{Assim}_{i j}^{\prime} \beta_{1}+\mu M_{i j} \\
M_{i j}=X_{i j}^{\prime} \beta_{0}+\operatorname{Assim}_{i j}^{\prime} \beta_{1}+M M k t^{\prime}{ }_{i j} \beta_{2}+e^{\prime}{ }_{i j}
\end{gathered}
$$

where the sub-indexes $i$ and $j$ refer to the individual and the marriage market respectively. As before, $M M k t$ includes variables defining the marriage market of the individual, such as the probability of meeting a potential partner of the same ethnicity within the marriage market, or the sex-ratio in the individual's marriage market. These variables are assumed to be exogenous and not to affect earnings other than through their influence on the probability of intermarriage. The system of equations can then be estimated by two step linear square methods. $^{19}$

In their study on intermarriage and assimilation, Meng and Gregory (2005) compare the earnings of different types of couples in Australia and find a substantial intermarriage premium for immigrants of approximately $20 \%$ for men and $46 \%$ for women. ${ }^{20}$ Natives on the other hand have much smaller intermarriage premiums, which suggests that higher earnings are the result of faster assimilation among intermarried immigrants, rather than the result of unobserved characteristics for immigrants who intermarriage. A similar result is observed for French immigrants (Meng and Meurs, 2006). Kantarevick (2004), however, reaches the opposite conclusion for US immigrants. The difference in results is likely driven by differences in the composition of the immigrant population in the two countries.

Nielsen, Smith and Celikaksoy (2009) use a reform of the immigration Danish policy

\footnotetext{
${ }^{19}$ This specification corresponds to a model estimated over married individuals. Alternatively, it could be applied to a full sample of individuals, where $M_{i j}$ is a two dimensional vector of endogamous and exogamous marriage indicators and single is the omitted category. The model can be further disaggregated by ethnic group.

${ }^{20}$ These numbers are the result of the two-step estimation. Estimating an equation similar to (1), assuming marriage exogenous, results in estimates of the intermarriage premium for immigrants of $5 \%$ for immigrant males and $10 \%$ for immigrant women.
} 
restricting "migration marriage”. The law effectively bans family reunification for unions in which one of the partners is below 24 years of age. Because the policy reform affected marriage behaviour of immigrants from different countries differently, it generates exogenous variation in marriage behaviour that can be used for identification of the causal effect of immigrant marriage on education outcomes of the children of immigrants, in particular on their dropout rate before the end of compulsory schooling. The authors find that the dropout rate of males increases by 25 percentage points as a consequence of marriage to a marriage migrant (or imported bride), whereas the effect for females is small and mostly insignificant.

\subsection{Assortative Matching in Education and Language}

Educational attainment and language proficiency among immigrants have received special attention within the literature as determinants of intermarriage. This is probably due to the importance that these variables have as predictors of successful economic integration for immigrants. To the extent that endogamy reinforces the traits of the ethnic community, the understanding of how language and education affect intermarriage decisions could explain the speed of intergenerational assimilation. Hence, the role of assortative matching in these two dimensions in explaining the marriage decisions of the second generation has been the subject of much interest. In an early study using the New Immigrant Survey Pilot, Jasso et al. (2000) find positive assortative matching in education among mixed marriages (US citizens and immigrant spouse), with similar levels of schooling within couples. However the levels of education across mixed couples vary depending on the gender of the US partner. US husbandimmigrant wife couples have over two years more of schooling than US wife--immigrant husband couples (that have around 12.5 years on average). Among immigrant couples, the educational attainment of both spouses is very similar when the wife is the principal applicant. When the male is the principal applicant he has on average two more years of education than his wife

Furtado and Theodoropoulos (2011) distinguish three main channels through which education can affect intermarriage. The cultural adaptability effect suggests that education might increase intermarriage because it makes immigrants more likely to accept the social 
norms in the host country and accept a native partner. ${ }^{21}$ The enclave effect proposes that as more education is associated with more disperse labor markets and mobility outside the ethnic enclave (Wozniak, 2010), it lowers endogamy by potentially reducing the size of the coethnic marriage market. Finally, the possibility of assortative matching indicates that the level of educational attainment of an individual will affect the size of the pertinent marriage market. According to the assortative matching theory, similar levels of characteristics increase surplus within marriages. Therefore, potential partners with similar levels of education may be willing to substitute similarities in ethnicity for similarities in education. Through this channel, education might or might not increase the probability of intermarriage depending on the distribution of education within the population. For instance, for a relatively highly educated individual, it would decrease the probability of endogamy among those belonging to immigrant groups with average low education and increase it in highly educated immigrant groups.

The significance of these three mechanisms can be estimated employing a variation of the previous model that explicitly considers the education levels of the ethnic group and of the marriage market:

$$
M_{i j k}=X^{\prime}{ }_{i j k} \beta_{0}+\gamma_{0} S_{i j k}+\gamma_{1} S_{i j k}\left(S_{j k}-S_{k}\right)+\operatorname{Assim}_{i j k}^{\prime} \beta_{1}+M M k t^{\prime}{ }_{j k} \beta_{2}+e^{\prime}{ }_{i j k}
$$

where $M_{i j k}$ is an indicator of endogamous marriage for person $i$ of ethnicity $j$ in marriage market $k$. The education indicators include $S_{i j k}$ that denotes an individual's years of schooling; $S_{j k}$ that refers to the average schooling of the ethnic group $j$ in marriage market $k$ and $S_{k}$ that measures the average schooling of the general population in marriage market $k$. Assim $_{\mathrm{ijk}}$ measures individual characteristics that account for immigrant assimilation such as generational status, age at immigration or language ability. $M M k t_{j k}$ measures other characteristics of the marriage market $k$ for ethnicity $j$, such as the relative size or sex ratio for the group, and controls for enclave effects. Finally, $X_{\mathrm{ijk}}$ is a vector of other individual characteristics that measure the taste for marrying within the same ethnicity, such as age (birth cohort) or ancestry. The effect of individual educational attainment is given by $\gamma_{0}$. If cultural adaptability plays a role, this

\footnotetext{
${ }^{21}$ Grossbard-Shechtman (1993) and Reinharz and DellaPergola (2009), however, suggest that certain types of ethnic or religious education may reduce intermarriage.
} 
parameter will be (or tend to) zero as education is supposed to reduce endogamy through this mechanism. The effect of assortative matching is captured by the interaction of an individual's education and the difference between the average education of the ethnic group in the marriage market and the average education of the marriage market. The corresponding estimated parameter, $\gamma_{1}$, is expected to be positive. If the ethnic group is more educated than the average in the marriage market, individual education will increase endogamy; however if the ethnic group has lower education than the average, high individual levels of education should reduce endogamy.

Most papers find empirical support for the hypothesis that education is positively associated with intermarriage (Meng and Gregory 2005; Qian and Lichter, 2007; Card, DiNArdo and Estes, 2000). ${ }^{22}$ However, not all of them distinguish between the different mechanisms. Furtado and Theodoropolous (2011), using the US census 2000, find evidence that the three mechanisms are at work. When there is no assortative matching effect - the average education of the group is similar to the average education in the marriage market one year increase in the education of an individual leads to one percentage point decrease in endogamy. On the other hand, when the education of the group falls below that of the general population by one year, endogamy decreases by 1.6 percentage points. The education of the ethnic group has to be one and a half years greater than that of the general population for a one year increase in individual education to lead to an increase in endogamy. The assortative matching effect is stronger for the native born than for immigrants, and stronger for immigrants arriving as young children than for older immigrants. Using an identical model on data from US census 1970, Furtado (2012) finds less support for the cultural adaptability effect of education after controlling for the other mechanisms through which education may affect the probability of intermarriage. She finds, however, robust evidence for the assortative matching mechanism among the second generation of immigrants in the US: within ethnicities with lower than average education levels (Mexican), the highly educated are more likely to intermarry than the less educated. The opposite is true for ethnicities with higher than average education levels (Russian), where endogamy is more prevalent among the higher

\footnotetext{
${ }^{22}$ Curiously marriage decisions among Asian females do not appear to be sensitive to education but seem driven by strong preference for ethnic endogamy (Dribe and Lundh, 2011; Furtado and Theodoropolous, 2011).

Chiswick and Houseworth (2011) find a similar result for female immigrants speaking Japanese or Korean and attribute this to the prevalence of war brides from these origins.
} 
educated. $^{23}$

Celikaksoy et al. (2006) also find support for positive assortative matching in education. They specifically tests the probability of marrying a spouse with similar levels of education among a sample of Turk, Pakistani and Yugoslavian immigrants to Denmark; hence their model does not distinguish among different mechanisms. However they make use of a rich set of cultural and family related variables to distinguish between individuals who are more culturally assimilated in the country of reception or who are in conflict with their parents and those who are not. Assortative matching seems to be stronger for Turks and Yugoslavian who are more culturally assimilated in Denmark but experienced conflict with parents and for the sample of not culturally assimilated individuals of any of the three countries of origin.

Most of the studies reviewed above include language ability as a control in the regressions of intermarriage and find that higher proficiency in the language of the country of destination reduces the probability of endogamous marriages. One problem with the use of this variable in the econometric models is its potential endogeneity. Individuals with better language skills may have other unobservable characteristics that favor intermarriage. In an interesting study, Bleakley and Chin (2010) look at the effect of language ability on several immigrant outcomes, including the probability of marrying, the probability of marrying a native born and the probability of marrying someone of the same ancestry. They are able to account for the potential endogeneity of language ability by using variation in age at immigration between immigrants from English speaking and not English speaking countries to instrument language ability. We go over this strategy more in detail in Section 4. Their results on language ability are similar to those reported elsewhere in the literature, which suggests that the effect of language on intermarriage is robust to endogeneity considerations.

The assortative matching model can be easily extended to account for the possibility of status exchange between immigrants and native born if intrinsic traits, such as citizenship, are part of the preferred set of characteristics immigrants look for in a spouse. Status exchange refers to the practice of exchanging acquired traits (wealth or education) for ascribed traits

\footnotetext{
${ }^{23}$ Additional evidence of both mechanisms is found in Chiswick and Houseworth (2011) using the 1980 US census. They report that education increases exogamy among immigrants (cultural adaptability) and that differences with respect to the modal education of the ethnic group increase exogamy (assortative matching). They do not account, however, for the relative education level of the ethnic group.
} 
(citizenship or belonging to a chaste/social class). In many countries, due to the long periods of residence required before individuals can naturalize, citizenship is easier to achieve through marriage, and in some cases it might be the only way to gain entrance into the country. Choi et al. (2012) in a US-Australia comparative study find evidence of status exchange, particularly among less-educated spouses and to a greater degree in the US than in Australia. Conversely, Liang and Ito (1999) find no evidence of status exchange among five Asian-American groups.

\subsection{The Timing of Family Formation}

A different dimension along which immigrants and native born may differ is their timing of family formation. Studying the timing of marriage among adult immigrants is complicated. On the one hand, as noted above, immigration and marriage could be jointly determined if marriage markets are thin or spousal visas facilitate immigration, encouraging migration as an established couple. ${ }^{24}$ Alternatively, if immigration completely disrupts the marriage market of the immigrant, it could be the case that recent immigrants take longer to marry than similar native-born individuals. In addition to these difficulties, information about the timing of marriages outside the country of destination, or even at the time of migration, might not be readily available. Researchers may lack information on the date of the marriage, as typically occurs when employing census data. Nevertheless, some studies show that most immigrant groups in Europe are likely to marry earlier than the natives. In contrast, the study of the timing of marriage decisions of the children of immigrants typically reveals a later age of first marriage than first generation immigrants, although still earlier than that of the native born (Algan et al., 2010; Constant, Nottmeyer and Zimmerman, 2010; Bisin and Patachini, 2012; De la Rica and Ortega; 2010; Giorgiadis and Manning, 2011)

In Europe, particular attention has been given to the marriage patterns of those of Turkish ancestry. In a cross-country study of second generation Turks in Europe, Huschek, Liefbroer and de Valk (2010) uncover a higher rate of first marriages among second generation Turks in the Netherlands, Belgium, Sweden and Austria relative to those in France, Germany and Switzerland. The authors establish parental and peer influences as important determinants of first union’s rates, but more interestingly, the cross-country nature

\footnotetext{
${ }^{24}$ The proponents of the family formation hypothesis highlight that marriage occurs in many instances in synchronization with migration and some put forward methods to measure the interrelatedness of those events (Mulder and Wagner 1993).
} 
of the data allows them to assess the influence of the institutional framework in which marriage decisions take place. The results suggest that welfare policies directed at helping youth to set up their own households (such as affordable housing) affect the transmission of cultural practices regarding marriage among the second generation, by easing out the material dependence on parents and may speed up union formation. Milewski and Hamel (2010) use the same data source restricted to France, and find significant differences in marital behavior between women of Turkish descent in France and natives. In particular, French-Turkish second generation women tend to marry earlier and are more likely to enter marriage directly without previous cohabitation than women without immigrant background. They are also more likely to marry a Turkish immigrant, rather than a second generation Turk or French native born

\subsection{Cohabitation}

The increase in cohabitation and the delay in marriage in most immigrant recipient countries, both part of the second demographic transition (Lesthaeghe and Neidert 2006), have changed the "reference" native-born family to which immigrants may adapt and hence influence the extent of immigrant "assimilation” to the host country's marriage or divorce patterns. Studies examining the prevalence of cohabitation among immigrant couples are far less abundant than those that analyze intermarriage as a form of immigrant assimilation in mainstream society of the host country. ${ }^{25}$ Standard models of cohabitation attribute the increase in the share of cohabitating unions to a change of individual (and societal) preferences that favors a trial period preceding marriage. As a result these models consider the influence of variables that account for uncertainty in future marriage, such as age, education level, and partner's place of birth, financial security or previous living arrangements on cohabitating unions (Bumpass and Lu, 2000). For immigrants, additional variables (such as generational status, cultural background, age at migration or years since migration) are brought into play to account for assimilation and are expected to play a role similar to that in intermarriage models.

Given the wide dispersion of rates of cohabitation across countries, the importance of taking into account an individual's cultural background when explaining cohabitation stems

\footnotetext{
${ }^{25}$ See Bernhardt, Goldscheider, Goldscheider, \& Bjerén (2007) for Swedish patterns and Trilla, Esteve and Domingo (2008) for Spanish patterns.
} 
from the fact that the extent to which observed cohabitation may reflect assimilation to the norms of the destination country should be understood with this cultural context in mind. For instance, as cohabitation is far more common in Latin American than in Asian countries, immigrant cohabitation is expected to be more common among Latin American immigrants, even amongst those from the first generation. Further, cohabitation among the children of Hispanic immigrants to the US, for instance, may indicate affinity with cultural ancestry rather than with US society, hence cannot be readily interpreted as a sign of assimilation.

Brown, Van Hook, \& Glick (2008) compare cohabitation by generation status and race/ethnicity and suggest that levels of cohabitation increase (linearly) across generations for all racial and ethnic groups. Across origins, they are the lowest among Asians (2.4\% for the first generation Asians) and highest amongst Puerto Ricans (12\% amongst first generation). ${ }^{26}$ Generational differences in cohabitation are significant and they typically increase for all immigrant groups. However these changes are particularly striking for Asians, for whom consensual unions more than double by the third generation. Mexican cohabitation rates increase almost $50 \%$ by the third generation, whereas for other Hispanic groups their cohabitation rates double. Patterns of cohabitation uncovered in this study are consistent with the idea that the second generation increasingly enters in cohabitation as a way of delaying marriage while, among other things, they invest in human capital. In Spain, the major foreignborn groups (Moroccans, Ecuadorians, Colombians and British) are more likely to cohabitate than the native born, but the large differences are accounted for by demographic characteristics of the immigrant population such as age, citizenship and education level as well as the couple characteristics, such as being in an endogamous relationship. This is however, not the case when considering the determinants of endogamous unions among immigrants. The likelihood of Colombians or Ecuadorians to be in an endogamous relationship remains high even after accounting for individual and union characteristics. (Trilla et al., 2008).

\subsection{Stability of Marriage}

Becker, Landes, and Michael (1977) model emphasizes the role of uncertainty and

\footnotetext{
${ }^{26}$ Interestingly the generational patterns of cohabitation diverge from those of marriage, which follow a U-shaped curve, being high for the first generation, low for the second and high again for the third generation. This is attributed to the importance that legal marital status may have for family reunification or joint migration.
} 
imperfect information in accounting for divorce. While gains from marriage are expected to be positive ex-ante, they might be negative ex-post when new information about the spouse characteristics or the outside offers to the marriage becomes available. Changes in social norms have increased the market value of women's time and prompted an increasing role of the state in regulating and enforcing monetary compensation following divorce. These factors contribute to reduce the costs of divorce, and possibly account for part of the increase in the rate of divorce in the US in the 1960s and 1970s (before slowly decreasing to a relatively high level) (Stevenson and Wolfers 2007). To the extent that immigrants might have different norms regarding marital dissolution, or might lack information about divorce regulation in the host country, divorce rates are bound to be lower among them. Lower educational attainment among some immigrant groups on the other hand may push marital instability upward (Lehrer 2003).

The characteristics commonly associated with an increase in the risk of marital disruption are (a) age/cohort-specific influences, (b) premarital experiences, (c) socioeconomic resources, and (d) couple-level characteristics. Higher tensions due to cultural differences and lower socioeconomic resources due to social disapproval of intermarriage are potential threats to the stability of heterogamous marriages which may increase their rates of divorce. On the other hand, individuals who have formed a mixed marriage maybe particularly endowed to succeed at relationships.

To assess the effect that these factors have on the likelihood of observing a divorce among mixed-unions, researchers could estimate the following simple model

$$
D_{i k j}=X^{\prime}{ }_{i k j} \beta_{0}+\text { Spouse }^{\prime}{ }_{i k j} \beta_{1}+k \beta_{2}+e^{\prime}{ }_{i k j}
$$

where $D_{i k j}$ is an indicator variable for whether individual $i$, in area $k$, of cultural origin $j$ reports being divorced. The vector $\boldsymbol{X}_{i k j}$ contains controls for gender, education, premarital experience, and other individual characteristics that may affect divorce rates, including socioeconomic characteristics. Spouse is a vector that controls for individual $i$ spouse's characteristics including whether or not they belong to the same cultural group. Fixed area effects, $k$, such state, provinces or metropolitan areas, are included to control for different laws or attitudes regarding divorce. The sub-index $j$ can designate different cultural manifestations, such as race, immigrant status, or religious beliefs. 
The empirical evidence universally agrees on the idea that heterogamous marriages experience lower stability and higher risk of divorce than co-ethnic marriages (McPherson, Smith-Lovin, and Cook, 2001). There is, however, wide diversity by specific racial groups (Bratter and King, 2008) and the type of inter-faith unions (Kalmijn, de Graaf, and Janssen, 2005, Lehrer and Chiswick 1993). In their study of the stability of racial intermarriage in the US, Bratter and King (2008) document that the percentage of couples divorcing after 10 years of marriage was elevated among interracial marriages compared to marriages in which couples are of the same race, particularly among more recent marriage cohorts. Although these numbers refer to the overall population, controlling for immigration status does not seem to change the probability of divorce. Interracial couples and mixed-status couples (foreign-born/native-born spouses) had similar risk of divorce than native-born couples. Nevertheless, couples where both spouses are foreign-born have a lower risk of divorce than those formed by two native born spouses (Zhang and Van Hook, 2009). Jones (1996) observes that the risk of divorce among mixed groups falls in between the divorce patterns of the involved groups if individuals more likely to succeed in marriage are the ones who intermarry. Kalmijn, Loeve and Manting (2007) study the effect of household income and the relative weight of wives' and husband's income on the probability of union dissolution and conclude that while higher levels of income reduce the risk of dissolution, marriages where females are the main earners in the household are at higher risk of dissolution.

A way of gaining a better understanding of how different factors affect union dissolution between groups is to use decomposition techniques to isolate the impact of compositional effects (effects due to differences in the mean values of the risk factors among groups) from other "unexplained" effects. This decomposition technique allows researchers to perform counterfactual exercises such as calculating dissolution probabilities for one group, conditional on having the compositional characteristics of the other. In an interesting study, Phillips and Sweeney (2006) undertake such decomposition method when looking at a wide range of risk factors affecting marital dissolution for Mexican women. They decompose the difference in marital dissolution probabilities between US-born and foreign-born Mexican women into a component due to differences in means of the risk factors (US-born Mexican women have more education, are more likely to work, to have cohabitated or to have had a child before marriage than foreign-born Mexican women) and other unexplained factors. 
They find that the probability of disruption among US-born Mexican women would diminish by $25 \%$ if they had the same compositional characteristics than Mexican-born women.

Immigration has been used to disentangle the effect of cultural norms and institutions on divorce rates. Furtado, Marcen and Sevilla-Sanz (2011) study divorce rate among European immigrant children to the US. They exploit the fact that child immigrants grew up with the host country institutions, but likely still exposed to the cultural norms of their home country through their family to study the effect of culture on divorce. A simple modification of equation (4) can be used to estimate the effect of culture on a sample of child immigrants

$$
D_{i k j}=X^{\prime}{ }_{i k j} \beta_{0}+\text { Spouse }_{i k j} \beta_{1}+k \beta_{2}+\beta_{3} D R_{j}+e^{\prime}{ }_{i k j}
$$

where $D R_{j}$, is a measure of culture, such as the divorce rate in country of origin $j$. Although Furtado et al. (2011) cannot control for spouse characteristics, they find that culture has a strong impact on divorce rates and that these effects differ by gender. Similarly, Mieke et al. (2011) exploit different types of endogamous marriages to separate the effect of cultural differences and social support on the probability of divorce. They look at endogamous marriages in which one of the partners migrated through marriage to a more established immigrant. This could, arguably, bring tensions due to cultural differences within endogamous marriages. Since marriage to a partner from the country of origin is usually supported by family and minority group, higher rates of divorce among this type of endogamous union (versus other endogamous unions) could be interpreted as evidence of the isolated importance of cultural differences on divorce rate. The study finds that these marriages generally display a higher risk of divorce than other endogamous marriages and this seem to be driven by increased cultural differences between the spouses.

\subsection{Family Reunification Policies and their Impact on Marriage Formation}

Immigration policy shapes many aspects of family life for immigrants, such as whether an spouse can legally migrate, the order in which family members arrive, or the size of the marriage market available. Employed-sponsored immigrants or refugees are likely to have distinct family formation patterns from other immigrants. Overall, studies accounting for immigration policies are scant because few surveys contain detailed information on categories of admission or on the timing of migration for all members of the same family that 
will be necessary to study these effects (Jasso, Massey, Rosenzweig, \& Smith, 2000).

Immigration policies also shape the size of the marriage market for immigrants. In the early $20^{\text {th }}$ century, US, UK and Canada restricted family reunification and often restricted female migration, hence hindering family formation and/or forcing intermarriage. ${ }^{27}$ Sometimes, sudden changes in immigration policies provide exogenous variation in the flow of immigrants and give the opportunity to study marriage or other immigrant behaviour. That is the case of Denmark, where a recent change in immigration policy tightened family reunification policies, in response to the increase in "marriage migration". Nielsen, Smith and Celikaksoy, 2009) use this policy change to study the causal effect of marriage on education, as already discussed in this section.

\section{Fertility}

The analysis of immigrant fertility differentials helps to understand the socio-economic integration of immigrant women, and the changing shape of family structure in immigrant recipient countries. Fertility decisions influence and are influenced by educational and labor market participation decisions, which makes them a key indicator of immigrant social integration, particularly for women immigrants. In addition, fertility estimates by ethnic group and generational status have the potential to improve provide more accurate scenarios for population projections in immigrant recipient countries.

\subsection{Microeconomic Models of Fertility}

In 1960, Becker suggested in his article on "An Economic Analysis of Fertility" that fertility could be understood as parental demand for children and hence treated using standard consumer theory. Women make fertility choices under a set of constraints (e.g. economic, educational and/or institutional) and with a given set of social attitudes towards fertility, contraceptives, gender preferences, out of wedlock childbearing related to social norms and expectations of both destination and origin societies, One of the most important insights of Becker's paper was the hypothesis that the cost of children is partly endogenous because utility arises from both the quality and quantity of children. Therefore, an increase in family

\footnotetext{
${ }^{27}$ See Ralston (1999) for more information on the Canadian case.
} 
income might be devoted largely to increase the expenditure per child (quality) rather than to increases in the number of children. Later, Willis (1974) presented a model of fertility that integrated Becker's quality-quantity tradeoff with a model of household production and human capital investment (based on Becker's (1964, 1965) and Mincer's (1963) earlier work). The model predicts a negative relationship between income and fertility due to assumptions on the value of women's time and the quantity-quality interaction Willis (1974) and Lewis (1971).

In the context of immigration, Becker's model has distinct implications. If immigrants are generally perceived to have different preferences for fertility than the norm in the host country, their fertility rates are likely to differ. However, the change in economic environment brought about by migration and the cost of migration itself will have an effect on fertility that might reinforce or offset trends implied by different preferences. All these forces will determine the extent of assimilation or adaptation of migrants. The direction of the fertility change after arrival will of course depend on whether immigrants are originating from highfertility or low-fertility countries. Since most international migrants move from relatively less developed countries to richer countries and total fertility rates are generally higher in relatively poorer countries the general expectation has been that migrant's fertility initially exceeds that of the native born at destination (Ben-Porath 1973). However, as more recent literature has pointed out, the fast decrease of overall fertility everywhere in the world and the possible selectivity of immigrants within source countries may imply the reverse relation. Next we review the main theories developed to understand the different factors that impact the fertility of migrants.

\subsection{Immigrant Differential Fertility: Mechanisms}

Goldstein and Goldstein $(1981,1983)$ (and Hervitz 1985) are the first works that analyze the impact of migration on fertility in a more systematic way and explicitly identify three important mechanisms to explain the differential fertility behavior of migrants: selection, disruption, and adaptation (see Figure 1). All three mechanisms are likely to shape the fertility of women who migrate as adults, and the independent role of each can be difficult to isolate and assess. Some of these mechanisms can happen together: it may be possible to observe an initial drop in fertility because of disruption at the time of immigration, followed by a 
subsequent rise in fertility, but also a gradual adaptation towards the fertility levels of the host country. ${ }^{28}$ These hypotheses have been tested in the literature, with none of them being conclusively accepted or rejected

[Figure 1 here]

\subsubsection{Selection}

The selection hypothesis posits that individuals who migrate differ systematically from nonmigrants in their countries of origin, and this selectivity may explain their subsequent fertility patterns (Forste and Tienda 1996, Kahn 1988, Sobotka 2008). Their fertility preferences may more closely resemble those of the destination country than the source country even before they arrive or they may have some traits that boost their labor market performance. Further, migration policies may reinforce the selection process. For instance, Canada has had long in place policies that target educated immigrants and reward knowledge in local languages, producing an average immigrant profile relatively more educated and closer to the native born than is typical in other destinations. These policy differences are prone to have important consequences for assimilation issues, including fertility adaptation In addition, if immigration is considered as a form of human capital investment (Chiswick 1978), individuals with more expected net benefits from migration and who are more forward looking may be the most likely to move and invest in other forms of their human capital at arrival. Those same individuals may be more prone to trading-off child quantity for child quality.

Although the majority of the migration literature recognizes the importance of taking into account selectivity when making inferences about migrant's behavior, few studies have been able to address this issue properly due to data constraints on pre-migration information of migrants and non-migrants in origin. ${ }^{29}$ Even if studies on international migration are constraint by the lack of appropriate information, some researchers have found ways to operationalized measures of selectivity to adequately analyze the data. Khan (1988) is the first most complete

\footnotetext{
${ }^{28}$ Some studies note this interaction of mechanisms and warn that immigrant fertility can be overestimated in TFR calculations when women's migration is linked to marriage and family formation (Dubuc, 2012; Milewski 2010; Toulemon and Pailhe, 2008; Kulu 2005).

${ }^{29}$ A few longitudinal studies on rural to urban migration are able to use information on pre-migration characteristics relative to the pool of potential migrants at origin which is in general lacking in studies of international migration (Rindfuss 1976; Courgeau 1989; White et al. 1995; Jensen and Ahlburg 2004; Kulu 2005).
} 
attempt to do this by using both aggregate information on fertility levels about the sending countries, and characteristics of the immigrants themselves. To understand whether immigrants are positively or negatively selected into the US she constructs a selectivity indicator by comparing the educational attainment of an immigrant cohort with that of the same birth cohort in the sending country. In particular, for each immigrant group the selectivity measure consists of the ratio of the proportion of female immigrants aged 40-44 in 1980 with at least one year of college, to the proportion of the sending country population aged 20-24 in 1960 that was enrolled in higher education at that time. Second, models include an interaction of origin-country fertility levels with individual educational attainment (as a proxy for individual selectivity) to understand whether the relevance of country values varies with education. In addition to standard demographic characteristics, her models include controls for three traditional measures to proxy assimilation, namely years since migration, language fluency and intermarriage. She notes that when thinking about convergence of fertility behaviors of migrants toward native levels, those who are positively selected relative to their sending-country populations are to some extent already assimilated before moving since they already resemble more the population at destination. In that regard, any norms from their countries of origin should play a lesser role in their choices than among those who are not selected. Her results show that immigrants are more assimilated in any of the measures (duration, intermarriage or language), they move away from the norms of their sending countries. Additionally, positively selected immigrants are the least influenced by those norms.

Blau (1992) analyzes migrant fertility with the 1970 and 1980 censuses. She calculates for each combination of country and years since migration in her data what proportion of women in the source country have the same or higher educational attainment as the respondent. She finds that in general, even if migrants have lower educational attainment than natives, they originate from the top third of the educational distribution in their country of origin. In a more recent paper Choi (2014) employs a similar method to show that Mexican migration to the US is selective of individuals with high fertility and high - relative to Mexican non-migrants educational attainment.

\subsubsection{Disruption}


The second mechanism draws attention to the (actual and anticipated) short-term disruption of fertility at the time of migration (Goldstein and Goldstein 1981; Stephen and Bean 1992). Migration may separate spouses at least temporarily, and individuals who are planning to move may postpone childbearing until after they are settled in their new home. This anticipatory behavior may cause a temporary drop in fertility prior to the move (that may be heightened by moving costs), followed by a rapid resumption (rebound) of fertility afterward (Goldstein and Goldstein 1981, Anderson 2004). This anticipation or reverse causality explanation suggests that childbirth reduces individual propensity to migrate, thereby making it more likely that migrants are childless on arrival (Toulemon 2004). The anticipation of benefits of having births in the country of destination may also be an additional mechanism that leads to a slowdown even before migration. In countries with “ius solis” regimes being born in the destination country will carry automatically all the benefits of citizenship. ${ }^{30}$

In addition there may be some economic disruption (as defined by Blau 1992) when the income of both wife and husband is temporarily depressed at the time of migration. A lower husband's income has a clear depressing effect on fertility, whereas lower women's wages have both an income and a substitution effect (lower opportunity cost of childbearing). Sufficiently large income effect will lead to a temporary slowdown in fertility until skills are upgraded or experience is acquired in the new labor market. Both mechanisms, the demographic and the economic, imply a slowdown of childbearing patterns around the time of migration (Stephen and. Bean 1992; Hervitz 1985). Nonetheless it is difficult to measure the extent of the disruption before migration since lack of pre-migration information and measures of selectivity interfere with this task. Evidence of short lived fertility disruption has been shown in Kahn (1994) and Blau (1992), for the US, Toulemon (2004) and Toulemon et al. (2008) for France, Garssen and Nicolaas 2008 in the Netherlands and Adserà and Ferrer (2013 b), Ng and Nault (1997) and Ram and George (1990) in Canada; in Jensen and Ahlburg (2004) for internal migrants in Philippines. Conversely, Mayer and Riphan (2000) do not find evidence of disruption in Germany.

\footnotetext{
${ }^{30}$ Another dimension of the relation between nationality laws and fertility concerns the investment parents undertake on children eligible for citizenship. Avitabile et al. (2014) show how, after the change in the rules that regulate child legal status at birth in Germany in 1990, birthright citizenship lead to a reduction in immigrant fertility and to an improvement in health and socio-emotional outcomes for the children affected by the reform.
} 
With regard to the fertility dynamics at the time of migration, the proponents of the family formation hypothesis, which is closely related to the disruption hypothesis, point to the potential interrelatedness between migration and family formation that boosts fertility immediately after arrival (Alders 2000, Anderson 2004; Milewski 2007,Sobotka 2008). They suggest that the elevated fertility after migration may not be entirely incompatible with the disruption hypothesis. Disruption may be occurring prior to migration, with the observed elevated fertility caused by the resumption of fertility after disruption. Lindstrom (2003) observes some short term elevated risk to first-births among women who move around the time of marriage in Guatemala, even though adaptation occurs for higher-parity births. Kulu (2005, 2006) presents similar results for internal migrants in Austrian, Estonian and Polish post-war birth cohorts and Singley and Landale (1998) for Puerto-Rican born women moving mainland.

Andersson (1984) applies event history techniques to the Swedish population registrar from 1960 to the 1990s to analyze the childbearing behavior of close to half a million foreignborn women. He finds a boost in the risk of childbearing, not only for first but also for higher parities, during the first years after migration to Sweden. However, after residing in Sweden for at least five year, fertility levels converge toward those of Swedish-born women. He argues that Swedish data do not support disruption at arrival, but that the immediate increase in fertility at arrival hints to a previous postponement or short-term disruption of childbearing in anticipation of the move. Given the interrelatedness of migration and family building processes, Andersson stresses the importance of controlling for time since migration in models of fertility.

With a similar methodological approach, Kulu (2005) allows the intensity models of conception to first birth to vary since time of arrival to destination to analyze whether there is some disruption around the time of migration within Estonia for post-war cohorts and also to better understand selectivity. In the same vein, Ford (1990) notes that studies of immigrant fertility that do not consider duration of residence are likely to be misleading. With data from the 1970 and 1980 US censuses, she finds that the immigrant fertility in the US rises after arrival perhaps to make up for births (and marriages) postponed before the move. Conversely, with the same data and tracking the same arrival cohort over time for migrants coming from 
high-fertility countries, Blau (1992) finds evidence of some short-lived disruption followed by an increase in the immigrant fertility towards the natives' level. Carter (2000) overcomes some of the limitations of cross-section data in the previous papers by using event history analysis with birth history data to better track childbearing patterns of Mexican migrants during the years around migration to the US. She finds it converges toward native levels after increasing immediately after immigration.

Two last methodological approaches have been employed to analyze the existence of disruption. First, instead of just considering duration in destination or years since arrival, Mayer and Riphan (2000) use the 1996 wave of the German socioeconomic Panel (GSOEP) to estimate a Poisson model of fertility that includes a measure of the fertile years spent in Germany. By creating a spline function of fertility years in destination it introduces a flexible specification to estimate differences in fertility around the time of arrival. Finally, researchers who use large registrar or census data and, as a result lack longitudinal data or complete birthhistories tend to compare the ratio of infants or of children aged under 5 in migrant households (for different years since migration) to comparable native households (Ng and Nault 1997; Adserà and Ferrer 2013b).

In general, since the actual disruption, if it occurs, is likely to be short-lived and only impact the timing or spacing of births, it is not expected to explain large aggregate differences in the cumulative number of children ever born, though research remains inconclusive (Goldstein and Goldstein 1981, Carlson 1985, Ng and Nault 1997, Ram and George 1990, Sobotka 2008). In a recent paper, however, Choi (2014) finds that initial disruption in the fertility of Mexican migrants to the US has lasting impact on the quantum of fertility. The innovation of her paper is to analyze characteristics of the population pre-migration and compare those who migrate with those who do not in the same birth cohort.

\subsubsection{Adaptation}

The adaptation hypothesis (or assimilation hypothesis, as referred by many economists) posits that as migrants settle in their new environment their fertility norms and expectations begin to resemble those of the native population (Goldstein and Goldstein 1981; Stephen and Bean 1992; Alba and Nee 1997, Lindstrom 2003). Ben-Porath (1973) is one of the first to 
show this with Israeli data. This is at odds with those who propose the Socialization hypothesis that notes that fertility preferences are determined by the country where migrants spent their childhood (Hervitz 1985). Thus, for those researchers, adaptation only happens among the second generation.

The speed at which newcomers adapt to the fertility of the destination country may be endogenous to opportunities offered to migrants (e.g. labor market, education, political participation and social integration; to the host country's cultural expectations and policies toward immigrants (e.g. multiculturalism) (Abbasi-Shavazi and McDonald, 2000); and to demographic policies in the country of origin either pro-natalistic (e.g. Ceceascu's regime in Romania) or restrictive (e.g. one child policy in China) that have shaped fertility of migrants, among other things. The interaction of migrants with host country economic and social environment, both in terms of opportunities and costs, mediate their ultimate fertility decisions. Immigrant women facing better labor market prospects in the host country may decide to reduce/postpone fertility in order to work in the same way as natives have already done as their opportunity costs of childbearing have risen -with technological change and relative gains to women's relatively abundant skills (Galor and Weil, 1996). Absence of informal child care provided by relatives and the need to resort to more expensive forms of formal daycare increases the incentives to trade off children for work (see Carter 2000 for Mexicans in the US) and to devote more resources to the rearing of each child rather than increase their offspring (Becker 1981).

The fertility adaptation mechanism has received more attention in this literature than other mechanisms not only because it can be interpreted as a sign of immigrants' social integration, but also because it has strong and long reaching implications for immigrant well-being, that extend to the second generation. As a matter of fact, a large share of the most recent research that explores the adaptation hypothesis has focused on the outcomes of individuals who migrated as children (Adserà and Ferrer, 2013a; Adserà, Ferrer, Sigle-Rushton and Wilson, 2012; Bleakley and Chin, 2010) and the second generation of immigrants (Dubuc, 2012; Parrado and Morgan, 2008). The next subsections of the chapter review in detail research on the pathways and heterogeneity of the adaptation process across destinations and source countries. 


\subsection{Duration in Destination and Age at Arrival}

The economics of migration literature has long recognized age at immigration as a decisive factor to explain the differential process of adaptation of immigrants in many socioeconomic dimensions (Chiswick 1991; Picot et al. 2005, 2007; Ferrer, Green and Riddell 2006). From Chiswick’s (1978) groundbreaking article in this field, the age at arrival has been used mainly to calculate duration in destination. Linear and nonlinear specifications of variables indicating years since migration have been regularly included in models aiming at measuring assimilation, particularly in labor market outcomes. The age at arrival may be also important on its own since it determines the moment in the lifetime at which immigrants are exposed to different spheres and social interactions in the country of destination (e.g. attending or taking children to school, participating in training programs or in different segments of the labor market) as well as the intensity of those interactions. Further there may be some critical ages by which socialization occurs for some outcomes (e.g. puberty) or by which some particular skills are learnt (e.g. language).

Most early research on the role of duration has focused the adaptation of the fertility of Mexican migrants to the US level. Part of this literature notes that the relative high fertility of Mexicans at arrival is explained by pronatalistic norms in their country of origin but that with duration in destination the relevance of those norms decreases and migrants assimilate to US levels (Ford 1990; Rindfuss and Sweet 1977). Ford (1990) controlling for duration in the US finds progressive adaptation after initial disruption and catch-up at the time of the move. Still, other researchers argue that barriers that result in limited social mobility by Mexican immigrants difficult their adaptation process. Thus lower opportunities in the destination local markets explain stubbornly high fertility (Forste and Tienda 1996, Frank and Heuveline 2005, among others). Frank and Heuveline (2005) do not find evidence of adaptation among Mexican migrants who have lived in the US for 12 years or more. They add to their models information on Mexican fertility at origin to understand the direction of adaptation, but, given common data restrictions in this literature, they measure it for the whole population instead of limiting the sample to those who eventually migrate or are more likely to do so in the future to account for selectivity. Unfortunately their lack of longitudinal information restricts their ability to obtain proper inferences of changes in the degree of adaptation across migration cohorts. Carter (2000) overcomes some of these limitations by using event history analysis 
with birth history data to better track childbearing patterns of migrants during the years around migration. She finds that, after increasing immediately after immigration, the fertility of Mexican migrants decreases over time, but remains above Mexican American levels.

Most of this earlier work has analyzed the assimilation of immigrants employing a unique cross section of data and comparing the fertility by years since migration. However, with a unique cross-section results may be confounded by migration cohort effects. It is not possible to distinguish between the effect of duration in the country of destination and cohort effects; that is, migrants who arrive to the same destination at different points in time may have differential fertility behavior. These differences may arise from changes in migration policies and the composition of migrants as well as economic and political circumstances both in origin and destination. To overcome this constraint Blau (1992) applies the synthetic cohorts’ method, based on Borjas (1987), to the analysis of fertility assimilation of migrants. Still the synthetic cohort method is subject to problems of selective return migration.

Blau (1992) examines first generation immigrant women in the 1970 and 1980 censuses, most of who arrived in the preceding decade (65\% and $58 \%$ in each census). She estimates a reduced-form model of the individual level fertility in each of the census years separately for immigrants and natives by ordinary least squares. ${ }^{31}$ Combining the results of the two regressions she is able to investigate the impact of years of residence in the US on the fertility of migrants by tracking a particular synthetic cohort over time while comparing it to similar natives at each time to determine the period effects. The adaptation or assimilation hypothesis implies a gradual convergence of immigrant fertility to that of natives over time. Still it is important to remember that short-lived disruption may depress fertility of migrants at arrival. Thus with data that spans only to a very short timeframe the estimated direction of migrantnative fertility differentials may be misleading of long-term trends in completed fertility differentials. Comparing the number of children ever born among older migrant and native women would circumvent this possible bias since these women would have already completed their childbearing years. However, as noted, it is not possible to extrapolate directly from the

\footnotetext{
${ }^{31}$ Blau (1992) also runs her analysis of synthetic cohorts separately for married women with spouse present and estimates both a reduced-form and a structural model of individual fertility for each year by nativity. The first model includes age, age square and education of the woman (and husband when present), years since migration and general demographic characteristics. In the structural model predicted husband's income and woman's wages are included instead of education.
} 
behavior of older migrant cohorts to predict that of recent cohorts because of potential changes in the ethnic composition and period conditions faced by new cohorts.

Looking at migrants coming from high-fertility source countries, Blau (1992) finds they have relatively similar unadjusted fertility to US-born women. In 1970, migrants have 0.07 fewer children than natives and only 0.18 more than them by 1980 . This is explained by some fertility disruption at arrival in the 1970 data and to immigrant women being positively selected in terms of education when comparing them to their source country. Those unadjusted differentials as well as their increase between the two censuses are important data on their own from a policy perspective regardless of whether they arise from differences in characteristics of migrants and natives or from their differential response to them. Adjusting for socioeconomic characteristics, immigrant women had fewer children in both census years and seemed more responsive to labor market opportunity trade-offs than natives. Tracking the relative fertility of synthetic cohorts throughout this period, Blau finds that fertility increases from 1970 to 1980, an indication of some initial disruption. For the cohort of immigrants who arrived in the period 1965-1970 the immigrant-native differential in fertility closes by 0.53 children from a gap of -0.63 children in 1970 to -0.1 in 1980 . For the cohort who arrived immediately before in 1960-64 the difference increases by 0.38 over the same period. Blau notes that with lack of further data it is difficult to ascertain the completed fertility of those cohorts and, as a result, the final immigrant-native differential. If trends continued though the average migrant of the first cohort would end up bearing over half a child more than a similar native.

A few studies have focused the fertility of immigrant women who arrived to their destination country before the age of nineteen. The reasoning behind this sample choice is that the disruption mechanism is unlikely to play any role in child migrants and even the selection mechanism is likely to be greatly attenuated, as migration decisions are mostly made by their parents and are plausibly independent of other variables affecting the child migrant's fertility. $^{32}$ Thus, by studying child migrants researchers have been able to focus in understanding the adaptation process in the receiving country and the role that age at

\footnotetext{
${ }^{32}$ Although Jasso (2004) points out that parental immigration to the US among Mexicans is partly influenced by the expectation of better prospects for their children.
} 
migration plays on it. Looking at child migrants has the additional advantage of exploring the existence of critical ages at which behaviors can be learnt (Bleakley and Chin 2010, Schaafsma and Sweetman, 2001). In the case of fertility, an additional effect of the age at arrival could arise if cultural norms regarding reproductive behavior formed at a particular age (for instance, the onset of puberty) are difficult to modify later on (Ryder 1973).

Among those who focus on migrants who arrived before adulthood, Adserà and Ferrer (2013a) use the Canadian Census of Population (20 percent sample) for the period 1991- 2006 to estimate a Poisson model on the number of children that includes a set of indicator variables for age at immigration, from under age 1 to age 18. They find that the fertility rate of individuals migrating up to age 6 is either somewhat lower or indistinguishable from that of natives while that of immigrants who arrived into Canada in their late teens shows a sharp increase relative to immigrants who arrived at earlier ages. The same age at arrival profile is present in England and France (Adserà, Ferrer, Sigle-Rushton and Wilson, 2012). Overall once researchers allow estimates of fertility to vary by age at immigration, they find patterns broadly consistent with the adaptation hypothesis. With few exceptions, women who immigrated at the youngest ages have fertility rates that are most similar to native-born women. Predicted fertility of migrants relative to natives in each destination calculated from basic Poisson estimates in Adserà, Ferrer, Sigle-Rushton and Wilson (2012) are shown in Figure $2 .^{33}$ It is interesting to observe such similar patterns of relative fertility rising with age at migration in countries with differences in both the extent of selectivity of migration policies and the geographic composition of incoming migration cohorts. Although in all three countries, at least since the 1980s, the fertility of immigrant populations has exceeded that of the native born (Belanger and Gilbert 2003, Adserà and Ferrer 2010), their contribution to overall fertility, while increasing, remains fairly small (Coleman, Compton and Salt 2002; Sigle-Rushton 2008; Herran and Pisson 2007). Nonetheless, the extent to which immigrants will sustain fertility over the longer term is less clear; as we discuss later in the section, evidence from Canada suggests that the fertility of second-generation immigrants may, in fact, fall below that of other native-born groups (Adserà and Ferrer 2010).

\footnotetext{
${ }^{33}$ The relatively small sample size in the French data compared to the large samples available in both the Canadian and English census explains the fact that the French predictions in Figure 2 are less smooth than those for the other two countries.
} 
(Figure 2 here)

\subsubsection{Age at arrival Language Proficiency and Critical Period Hypothesis}

As noted, another reason to focus on women who migrated as children and their age at immigration is that there might be critical ages at which individuals learn a particular behavior or skill, such as the local language, that are crucial for future social and economic outcomes. It is well documented that fluency in the language of the destination country decreases with age at immigration among other things (Chiswick 1991; Stevens, 1992, 1999; Espenshade and Fu 1997; Espinosa and Massey 1997; Akresh 2007) and should be greater for those migrants who arrive as children. Fluency in the language of the destination country has long been recognized to play a key role in immigrant's outcomes and degree of adaptation (see e.g. Kossoudji 1988; Dustmann 1994; Schaafsma and Sweetman 2001; Chiswick and Miller 1995 and 2001; Dustman and van Soest 2002; Bleakley and Chin, 2004). Studies by Leslie and Lindley (2001) and Dustmann and Fabbri (2003), for example, find that lack of fluency in English has a detrimental impact on the employment and earnings of ethnic minority men and women in Britain. In the case of fertility, a non-official mother tongue may impact the ability of the child-migrant to access local cultural cues through school and peers to form her fertility preferences. Existing analyses have found greater English fluency to be associated with lower fertility in the US (Sorenson 1988; Swicegood et al. 1988; Bleakley and Chin 2010) and Canada (Adserà and Ferrer 2013a).

The first two works to analyze the role of language focus on the fertility of all Mexican immigrants in the US. Sorensen (1988) takes advantage of new questions on language use and English proficiency introduced on the 1980 US Census. Her analysis focuses on endogamous Mexican American and non-Hispanic white couples living in Texas, New Mexico and Arizona in which the wife is between 40 and 44 years of age rather than on women's characteristics alone. She finds English use at home by both the wife and the husband decreases the likelihood of having an additional child at all parities even after controlling for educational attainment and English proficiency. Among non-Hispanics couples the likelihood to transit to parity five or more is also higher among those with low English proficiency who do not speak English at home, even after controlling for educational attainment and nativity. Swicegood et al. (1988) also employ the 5 percent Public Use Microdata Sample (PUMS) from 1980 US 
Census to find a negative effect of English proficiency on the total number of children ever born and in the presence of children under three in the household among ever-married Mexican American women aged 15-44. The relevance of English proficiency increases with education, particularly among the younger age groups. The authors argue that opportunity cost calculations rather than cultural factors play a more central role in shaping childbearing behavior of women in their sample.

A problem with estimating the impact of language proficiency on socio-economic outcomes is that proficiency is an endogenous variable and may be correlated with other variables that explain those outcomes such as ability or attitudes towards preserving the ancestral culture. As a result, ordinary least squares (OLS) estimates of the effect of proficiency of the destination language are likely unable to estimate the causal relationship. Bleakley and Chin (2010) use an instrumental variables strategy to circumvent the problem of the endogeneity of language fluency and show that the outcomes of immigrants from nonEnglish speaking countries systematically differ from those of other migrants only among those arriving after the critical period for language acquisition of 8 to 9 years of age. They employ microdata form the US Census 2000 to study how marriage and fertility, among other socioeconomic outcomes, of childhood immigrants (who arrived before age 15) currently between ages 25 and 55 are related to their age at arrival in US. Consistent with the existence of a "critical period" of language acquisition, there are no significant differences in adult English proficiency among immigrants from English and non-English speaking countries who migrated to the US very early in life. Moreover, while the relation between age at migration and English proficiency remains flat for those from English-speaking countries, proficiency decreases almost linearly with age at arrival for those from non-English speaking countries who arrived after age. Bleakley and Chin (2004, 2008, and 2010) use these differences between younger and older arrivers on English language skills to construct an instrumental variable for English proficiency. Since age at migration is likely to affect socioeconomic outcomes of migrants through channels other than language (e.g. better knowledge of US cultural norms) and, as a result, it may fail the exclusion restriction as an IV, they use immigrants from English-speaking countries to control for the impact of age at migration that is not related to language fluency.

In a first stage equation, they instrument language proficiency with an interaction between 
migrant's age at migration (beyond the critical age of nine) and an indicator for a nonAnglophone country of origin. Results show that the ordinal measure of English proficiency ( 0 to 3) decreases by 0.1 for each year that the immigrant arrives after age nine among those arriving from a non-English speaking country- a sizable effect. They use fitted values for English proficiency to estimate a second stage relationship for fertility outcomes of migrants first for all individuals in the sample and then separately by gender. The number of children present in the household of immigrants with higher English fluency is smaller than for the rest, even though English-proficient women are not significantly less likely to have a child. Among more English-proficient men the reduction in the number of children is also explained by differences at the extensive margin. However, there are not significant differences in the extensive margin when the sample is restricted to married men. Single parenthood or out-ofwedlock births are not significantly related to English proficiency. These findings are robust to controlling in the models for the interaction between age at arrival with either the fertility rate or the GDP per capita in their country of origin as well as to dropping either Canada or Mexico from the sample of migrants.

Adserà and Ferrer (2013a) estimate the fertility of migrants who arrived before age nineteen to Canada relative to that of natives by age at migration separately for those who have a mother tongue that is an official language in Canada and for those who do not. They do not employ an instrumental variable strategy but, instead include in their models interactions of dummy variables for each age at arrival before adulthood with an indicator of whether the mother tongue of the individual is official in their province of residence. Unlike Bleakly and Chin (2010), they do not find a sharp discontinuity in immigrant fertility behavior relative to natives among migrants arriving before or after the age of entry into middle school and whose mother tongue is not official in Canada. Moreover, fertility of both immigrants with and without an official mother tongue increasingly differs from that of natives by age of migration. However, fertility remains lower among immigrants with an official mother tongue than among those without it for any age at arrival.

\subsection{The Role of Culture: Heterogeneity across Source Countries and Adaptation}

The role of culture in explaining immigrant assimilation is pervasive. The extent of adaptation may hinge on the distance between the norms governing fertility in both the destination and 
source country. Those norms or attitudes are part of an individual's cultural background. Even if immigrants leave behind the laws and institutions of their home countries, they do bring a set of beliefs and traditions that may be slow to change and often get passed to their children. Across countries of origin there may be different norms and expectations regarding fertility such as age at first birth or acceptability of out-of-wedlock births. Unfortunately lack of premigration information generally limits the ability to study the direction of adaptation in the destination country. Further there may be differential selection across origins and employing country of origin averages as references might be misleading. Regardless of these limitations, accounting for heterogeneity of origins in the migrant population has proven to be relevant in explaining variation in fertility outcomes in different contexts (Kahn, 1994; Andersson, 2004; Coleman 2006; Georgiadis and Manning, 2011; Guinnane et al., 2006 and Parrado and Morgan (2008), among others).

The simplest way fertility models account for cultural background differences is by introducing country of origin fixed effects. ${ }^{34}$ The majority of such studies report substantial differences in fertility by ethnicity, with some groups adjusting their fertility faster than others. In Britain, Georgiadis and Manning (2011) and Coleman and Dubuc (2010) highlight the relatively slow fertility assimilation of Pakistanis and Bangladeshis as compared to that of other groups such as Chinese, Indians and Black Caribbean whose fertility is at or below the UK national average. In Germany, multiple studies mostly employing the German socioEconomic panel have shown foreign-born fertility to slowly converge toward native levels since the 1970s (Mayer and Riphahn 2000; Milewski 2007), particularly among Polish and Italians (Schulz 1978). Turkish migrants (and Muslim migrants in general) have always exhibited higher fertility than natives, but there is some evidence of adaptation as their fertility is lower than in Turkey (Kane 1986, Schoorl 1995). Schrool (1990) shows similar patterns in the Netherlands. Sobotka (2008) compiles data on TFR of immigrants from Somalia, Pakistan, Turkey, and Iran from different sources and compares it to western European levels. The fertility of these groups is relatively high compared to that of their country of destination, with

\footnotetext{
${ }^{34}$ Religion is an important determinant of fertility as it typically embodies a broad set of cultural rules surrounding childbearing. However, many surveys do not include questions on religion and many researchers proxy these differences using country of origin instead. A few papers analyze fertility across religious groups in developed countries (Adserà 2013, Westoff and Frejka 2007, 2008). Westoff and Frejka (2007) provide an excellent survey of the wide heterogeneity in the fertility of European Muslims depending on their ancestry and country of birth.
} 
the exception of Iranians. In Canada, research shows that up to 1980 Canadian immigrants had lower fertility rates than the Canadian born (Kalbach 1970), but the trend has since reversed. A study by Belanger and Gilbert (2003) suggests that the increase in the share of Canadian immigrants from areas with traditionally high fertility rates such as the Middle East, Southern Asia and Latin America is likely responsible for this change in fertility patterns. The literature findings underscore the importance of taking into account the heterogeneity of the foreignborn population and analyzing whether, once controls for origin are included in the empirical analysis, adaptation occurs in a similar way for individuals moving from different places.

In that regard, to study whether child immigrants arriving from certain regions adapt to the rules that guide fertility behavior in the host country faster than others with the same years of exposure, Adserà, et al. (2012) estimate a Poisson model that includes interactions of a set of age-at-immigration dummies with indicators for each world-region of birth. Results show patterns broadly consistent with the adaptation hypotheses with fertility rising with age at arrival in all three countries they analyze, Canada, France and England and Wales, and across all origin groups in each country. However estimates suggest that the estimated effect of exposure to the host country varies by origin and it is particularly important to explain fertility outcomes of immigrants who come from Africa and Asia to France and from South Asia to England and Wales.

To understand cultural norms that migrants bring with them when they move, some studies compare fertility patterns at origin and destination. Thanks to available census data, this has been done extensively for migrants to the US during the late XIX and early XX century. Guinnane, Moehling and O Grada (2006) study Irish fertility in the US using the 1910 IPUMS and fertility in Ireland with the 1911 Irish Census. They find that the fertility of Irish migrants is higher than that of comparable natives, but relatively lower than that of similar Irish couples in Ireland where marital fertility remained high throughout these years. To understand whether the persistence of source-country norms was specific to Irish migrants, they analyze the fertility patterns of German migrants. While they find that the fertility of first-generation German immigrants was also higher than that of native-born whites, the difference was vastly accounted for the socioeconomic characteristics of that population. Further, the fertility of the second generation of German immigrants was similar to that of the native-born population. Rosenwaike (1973) studies first generation Italian migrants with the 1910 and 1960 US 
Censuses and second-generation migrants of Italian ancestry with the 1960 Census. He argues that Italians brought with them patterns of very high fertility from their country, but those who migrated as children (and the second-generation) assimilated successfully to the lower fertility of natives. Gjerde and McCants (1995) analyze how, on the one hand, better economic opportunities at destination than in origin that encouraged high fertility and, on the other hand, cultural norms brought from the source country affected the marital and fertility decisions of Norwegian immigrants to the US. Data from the 1900 PUMS of the US Census shows that women of northern European countries in the upper Middle West US frontier had around one and a half more children over a marriage span than native-born. In their historical analysis of Norwegian migrants, they argue that fewer constraints to land access than those faced in their homeland allowed young couples to marry relatively early and have more children than in Norway. Those patterns changed for the second-generation and later arrivals when faced with more economic and population pressures that brought ancestral cultural norms (of late marriage and restraint fertility) back into the spotlight.

Finally, to better proxy cultural norms and expectations in origin, some researchers introduce direct and substantive information from source countries in their models with the understanding that dominant behaviors in a country are reflected in those norms. Khan (1988) uses a measure of the net reproduction rate (NRR) dating from the late 1960s, to proxy for fertility norms faced by the migrant women she studies in the 1980 US Census and finds it accounts for part of the cross-country differentials. Frank and Heuveline (2005) undertake a similar exercise when studying Mexican migrant adaptation.

Blau (1992) examines first generation immigrant women in the US 1970 and 1980 Census and finds that, among other things, their home country total fertility rate (TFR) is a significant covariate when explaining their childbearing behavior. Instead of just introducing country level variables as additional covariates in a model of individual fertility, she employs a two stage estimate to analyze their on the migrant-native fertility differentials by place of birth among immigrants once other observable characteristics are taken into account. In particular she estimates the following two equations

$$
F_{i}=X_{i}{ }^{\prime} B+D_{i} C+\varepsilon_{i}
$$




$$
C_{n t}=Z_{n t} B_{z}+Y_{1970}+\varepsilon_{n t}
$$

Equation (6) is a reduced form analysis of individual fertility $F_{i}$ that includes individual $i$ demographic characteristics $X$; a vector of country dummy variables $D$ and $\varepsilon_{\mathrm{i}}$ a stochastic error term. In equation (7), the dependent variable $C_{n t}$ is the vector of dummy variables for each country $n$ in the year $t$ estimated in equation (6). The model includes $Z$ a vector of country source variables, a dummy for year 1970 and $\varepsilon_{n t}$ a stochastic error term. The source country variables include total fertility rate (TFR), per capital GCP, the proportion of women in the source country with the same or higher educational level as the migrants, infant mortality, the proportion of refugees among migrants and the distance in kilometers between the US and the country of origin. Variables are constructed by weighting the country levels in each country and years since migration group by the distribution of immigrants in each of those cells. Not surprisingly, overall predicted levels of migrant fertility are lower than the total fertility rate at origin. Nonetheless, characteristics from source countries matter and explain fertility differences across nationality groups in the US. TFR in particular and to some extent relative low educational attainment exert a positive force on migrant fertility. As expected the relevance of origin variables increases with the age at arrival and for individuals who married in origin and married within their own ancestry.

As Fernandez and Fogli (2009) note, works that study the first-generation immigrants face problems of selection into migration as well as the possibility of delay, disruption and catch-up in fertility around the time of migration that can contaminate the inferences one makes about the strength of cultural continuities.

\subsection{Son Preference}

A controversial issue regarding immigrant fertility refers to the persistence of gender preference among some immigrant groups even after migration. Gender preference for children, in particular son preference, is deeply rooted in some cultures and usually associated with the economic environment. Developing rural economies might demand more sons who can better help with physical labor in the fields, and poor households might deem daughters too expensive in cultures where dowries are expected in order to marry them off. Traditional economies where males are the main provider of resources and with little social programs for 
old age will attach more value to male than female offspring. It is expected that in more developed societies with more equal gender roles in the labor market and where children are not as essential for old-age insurance, son preference should be less important and reflect only gender tastes. It is plausible, however, that immigrants arriving from areas with strong son preference should show some evidence of differential treatment of the offspring if their cultural preferences for a given gender persist well after migration. Pabilonia and Ward-Batts (2007) and Lhila and Kosali, (2008) show evidence of differences in parental labor supply and prenatal health behavior conditional on the gender of the child in developed countries by immigrants from countries with marked son preference, like China, India, South Korea and Taiwan.

Models of gender preference consider both tastes over offspring gender and the economic value attached to each gender as determinants of gender preference and their potential impact on fertility. In general, gender preference might increase fertility if births continue until the desired gender balance is achieved. However, economic conditions might limit the desired number of children and contribute to limit fertility, particularly if there is room for gender selection (Ben-Porath and Welch, 1976). Work by Klasen and Wink (2003) present recent evidence of dramatic sex ratio imbalances across different countries, particularly in South East Asia, that can only in part be accounted by selective abortion. Since incentives for sex selection are stronger at later births, high male to female birth ratios at higher parities can be interpreted as evidence of son preference and typically denote the existence of gender selection.

Using data from different sources (US Federal birth data 1971-2005, California birth data 1970-2005 and the 1980, 1990 and 2000 US Censuses), Abrevaya (2009) looks into the probability of the birth of a boy, conditioning on the gender of the previous child, for different ethnic groups in the US and finds substantially higher male to female ratios among Chinese and Indian women for the third and fourth child (and even for the second among Indian). These higher ratios of male births are associated with the use of gender selective procedures in pregnancies. The imbalance is larger for older women, for the third child and among less educated Chinese, but similar across educational levels among Indian women. The main findings in sex ratio imbalances in the US are confirmed by Almond and Edlund (2008). Indian immigrants to England and Wales also portray abnormal rations and Dubuc and 
Coleman (2007) tie this finding to a reduction in fertility of Indian immigrants to Britain not observed among other Asian-origin population (like Pakistani and Bangladeshi), who in turn maintain normal male to female birth ratios. Almond et al. (2009) use a similar methodology to determine the extent of gender selection among South East Asian immigrants to Canada. They find that religion is a strong determinant of high male to female birth ratios, with Christian or Muslim Asian immigrants (mainly from Pakistan, Bangladesh, Philippines and Hong Kong) exhibiting normal sex ratios, and other religions such as Hindus and Sikhs showing abnormally high sex ratios and that this persists to a lesser degree among second generation immigrants. The Canadian case is interesting because of the large size of the immigrant population arriving from countries with high sex birth ratios. With similar data, Adserà and Ferrer (2011) find that Sikhs and Hindus speed fertility up after the birth of two girls, but transit much slowly to third births after two boys are born. Those asymmetries do not appear across other religious groups. They also find significantly altered sex ratios: the likelihood of having a boy either after one or two girls are born increases among those born in south East Asia and among Sikhs. For both groups the bias in the ratios is large for births that occur very close to the previous birth.

\subsection{The Fertility of the Second Generation}

Because changes in fertility preferences might take more than one generation, research into the adaptation hypothesis also looks at second generation immigrants to investigate the extent of fertility convergence. Further, the policy relevance of understanding the assimilation of the second-generation is evident. In countries with substantial immigration inflows, a large share of the next generation will consist of individuals whose parents were born abroad. Even if the first-generation only assimilates partially to native patterns, their children may converge to native levels of education, labor supply or fertility as they adopt cultural cues in their country of birth and respond to local labor market opportunities. ${ }^{35}$ In this regard, even persistent native-immigrant fertility gaps would not bring about long-term changes of fertility patterns in the destination country.

Empirical studies overwhelmingly find that fertility differences present among

\footnotetext{
${ }^{35}$ The assimilation of the second generation has been extensively studied in many dimensions; see the chapter on second generation outcomes in this handbook by Sweetman and Van Ours (2014).
} 
immigrants tend to shrink (or disappear) among the second generation of migrants. The fertility patterns of second generation immigrants to West Germany (Milewski 2010) and second generation Turkish and Moroccan women in the Netherlands (Garssen and Nicolaas 2008) are closer to those of the native born than those of first-generation immigrants. The fertility of second generation immigrants to the UK tends to converge to the average fertility, with second-generation Pakistani and Bangladeshi women in particular having fewer children and at later ages, compared to the first generation (Dubuc 2012). Adserà and Ferrer (2010) find that the fertility of second generation Canadians resembles that of the native born more closely than that of their parents. Similar results are found in Australia (AbbasiShavazi and McDonald, 2000).

In the US, fertility patterns of some groups of immigrants seem to remain high even among the second and third generations (Bean, Swicegood and Berg, 2000). Blau and Kahn (2007) study the intergenerational assimilation of Mexican migrants and find very large differentials compared to native non-Hispanic whites in education, labor supply and fertility during the years 1994-2004. Even though the second generation closes much of those gaps, particularly in education and work, their fertility differentials with natives are still substantial. These findings are confirmed in Blau et al. (2008) who find positive but limited intergenerational transmission of labor force and educational outcomes of all immigrants to their US-born children. However, the fertility assimilation of second generation US immigrants seems to be slower than in other countries, as it remains $40-65 \%$ in excess of that of the native born.

In the same vein as some studies of the first generation just reviewed, one way the literature analyzes the culture and intergenerational transmission of norms is by looking at the outcomes of variables of interest in the countries of origin of parents or in general of people of the same ancestry as the individuals under analysis. Antecol (2000) uses the 1990 US Census to analyze whether female labor force participation (LFP) in the country of ancestry (measured in 1990) explains the gaps in women's LFP among the second-generation and beyond. She finds a weakly positive correlation. The fact that ancestry is self-reported is a limitation of the study. Instead of directly using data from the country of origin, recent work matches secondgeneration migrants to information on the characteristics of first-generation migrants from the same ancestry as their parents. These researchers generally employ the large samples of earlier 
censuses to construct these measures. Among them, using the 1970 US Census that collected data on foreign parentage, Borjas (1993) finds significant intergenerational transmission in wages and Card et al. (2000) also in educational attainment and marital assimilation in addition to earnings. Both papers use matched data from 1940 on immigrants from the father's ancestry.

Within this general methodological framework, Fernandez and Fogli (2006, 2009) and Blau et al. (2008) are the most distinctive papers that analyze the intergenerational transmission of fertility behavior. To understand the role culture plays in the fertility outcomes of the second generation they estimate some variation of the following general model

$$
F_{i s j t}=\beta_{0}+\beta_{1}^{\prime} X_{i}+\beta_{2} \tilde{Y}_{i}+\beta_{3} \tilde{F}_{j}+f_{s}+\gamma_{t}+\varepsilon_{i s j t}
$$

where $F_{i j s t}$ is the measure of fertility for a woman $i$ living in the Standard Metropolitan Statistical area (SMSA) or in a region $s$ at time $t$ and of ancestry $j ; X i$ is a vector of individual controls; $\tilde{F}_{j}$ includes the variables employed to proxy the cultural norms in the country of ancestry, $\gamma_{t}$ is a set of year of survey fixed effects (if more than one year-survey is employed) and $f_{s}$ a set of dummies for SMAS or region of residence and $\varepsilon_{i s j t}$ a stochastic error term. In some papers the model also includes $\tilde{Y}_{i}$ fertility characteristics of the individual's family (e.g. number of siblings a woman has in Fernandez and Fogli 2006).

Fernandez and Fogli (2009) use data from the 1970 US Census that includes information of parental origin. Their models include both the female labor force participation and the total fertility from the country of origin of the father of the respondent in 1950 as covariates to account for cultural norms. They find that TFR among migrants from the father's ancestry is significantly associated with fertility patterns of the second-generation. A one standard deviation increase in the TFR in 1950 is associated with approximately 0.4 extra children, a 14 percent increase in the number of children in 1970 (Fernandez and Fogli 2009: p.149). Additionally they run the same two stage model as in Blau, given by equations (6) and (7), to find that TFR and LFP in 1950 explain variation across estimated country-dummies. Results are robust to the inclusion of measures of the average human capital and of quality of education of migrants from the same ancestry. They employ the 1940 US Census to track average parental education of migrants from the father's ancestry. To understand whose 
culture matters most within a couple, Fernandez and Fogli (2009) create an indicator for whether the husband's father is of the same ancestry as the woman's father and generate two separate interactions of that indicator with the level of total fertility rates (TFR) and labor force participation (LFP) in the countries of the father of both the wife and the husband. In addition to the indicator for those couples sharing the same ancestry, these cultural proxies are positive and significant when included alone or simultaneously in all models and the size of the coefficients is similar for the wife's and the husband's ancestry covariate. In addition to see whether the ethnic density in their neighborhood, measured as the proportion of respondents' neighborhood of the same ethnicity, impacts fertility separately from the cultural indicator, they include the cultural covariates, the density and the interaction of both in the models. They find that ethnic density only matters when the fertility in the country of origin is included. The number of children increases by 0.19 with a one standard increase in the TFR of the country of origin in1950.

As Card et al. (2000) note, a constraint of employing measures of the characteristics of older generations of the same ancestry is the proper interpretation of the findings. Those covariates are bound to capture the impact of both the personal experience of the individual in his home while growing up as well as the ethnic capital or cultural referents associated with the outcomes measured by the covariate at the group-level. The estimated coefficients in these models capture the combined effect of both mechanisms. In an attempt to separately estimate these two mechanisms Fernandez and Fogli (2006) estimate a model as in (6) that includes both the total fertility rate in the country of ancestry in 1950 as well as individual characteristics directly related to fertility socialization, namely the number of siblings the woman has. They employ the General Social survey (GSS) for the years 1977, 1978, 1980 as well as 1982-1987. They find that the effect of culture, measured by the fertility in the country of origin, is quantitative important even after controlling for the number of siblings of the individual. A standard deviation increase in the 1950 TFR is associated with an increase of 0.14 children (half of the variation in the number of children observed across different origins in the US).

Instead of limiting the cultural controls for individuals of the same ancestry to the same year as previous analysis do, Blau et al (2008) allow this variable to vary with the birth cohort of the second-generation migrant. They use the 1995-2006 CPS March file, which contains 
information on the country of birth of each respondent as well as each of her parents, to estimate

$$
F_{i t}=\beta^{\prime} Z_{i t}+\sum_{c} a_{c} X_{c i t}+\varepsilon_{i t}
$$

where $F_{i t}$ is the fertility measure of an individual in year $t$ with a mother or father born in country c; $Z$ is a vector of controls, $X$ is the vector of age-adjusted immigrant parent characteristics (father and/or mother) and $\varepsilon_{i t}$ is the error term. Among other individual covariates, the vector $\mathrm{Z}$ includes dummy indicators for whether the father and/or the mother are immigrants as well as race and ethnicity indicators. However no controls for the respondent's marital status, education of location are included. Blau et al. (2008) combine information from the 1970, 1980, 1990 and 2000 US Censuses to construct a vector $X$ of parental characteristics that includes a set of controls on the fertility, labor supply and schooling of immigrants who were likely of the same age cohort as her parents. Thus respondents from the same ancestry have different variables attached depending on their age. Since the data expands to recent years, it is able to track compositional changes in the latest waves of immigrants, with a substantial increase of immigrants from Latin America and Asia coupled with a decrease on the weight of second-generation immigrants of European descent that constituted the majority in the previous papers in the literature. Considering for the first time maternal ancestry it is important since for 28 percent of their sample only the mother is foreign-born. The inclusion of information from both the father and the mother allows the authors to study the relative importance of the cultural norms from each parent. Results are robust to pooling all families together or separating them by foreign-birth of the father or of the mother and also by marital status. In general cultural continuities from the mother's ancestry are significant and stronger for fertility than the father's, though the latter are also positive. The sum of the impact of both effects, around 0.5 , is comparable across specifications and implies that one standard deviation increase in immigrant's ancestry fertility increases the second-generation's fertility by approximately 0.6 children. If stable for the next generation, at this rate of transmission, after two generations only around 25 percent of the excess fertility would remain.

\section{Conclusion}


Developed countries have seen the number and diversity of their foreign born populations increase substantially has and with them the interest in the contribution immigrants make to social and demographic trends. To a large extent, this interest originates from the fact that family formation is often used to measure immigrant assimilation and as such is an indicator of social cohesion. Furthermore family formation and many other key many household decisions are intertwined and have crucial implications for the role of migrant women in the labor market and the investments made in their children, the second generation.

This chapter discusses some of the challenges faced by researchers to estimating trends in family formation and union dissolution among immigrants with incomplete data, and reports the evidence collected from the main studies in the area. The literature on immigrant family formation is diverse but perhaps the two most robust results highlighted in this chapter are that outcomes depend greatly on the life-cycle timing of migration and on the cultural norms immigrants bring with them and on their distance to those of the host country. This underscores the importance of accounting for some measure of cultural origin to distinguish the complex path that each immigrant group follows to demographic integration in single country studies. In some cases adaptation is relatively quick, but in many instances it may take more than one generation for individuals with immigrant background to conform to the host country patterns in marriage or fertility.

Similarly, despite the scarcity of cross-country studies, the evidence suggests that the environment at destination also exerts a great influence in the demographic trends followed by different groups of immigrants. More research is called for in this area, as it remains difficult to distinguish between the effect of the host country on a particular group of immigrants and the selection mechanism that encourage different types of immigrants from a given source country to move to different destinations. Exploiting variation in immigration flows to different countries that share similar environments could help disentangling these effects.

Finally, our review highlights the importance of improving data availability on key variables related to the migration process and lifetime events such as detailed age at migration, complete union and birth stories and measures of language proficiency and mother tongue among others. Ample support should be given to some efforts already underway to construct 
datasets that include information of households at origin as well as destination to better compare migrants, non-migrants and returnees and address research challenges stemming from migrant selectivity. 


\section{References:}

Abbasi-Shavazi, M.J. and P. McDonald. (2000). Fertility and multiculturalism: immigrant fertility in Australia, 1977-1991. International Migration Review 35 (1): 215-242.

Abrevaya, J. (2009) Are there missing girls in the United States? Evidence from birth data. American Economic Journal: Applied Economics, 1(2): 1-34, 2009.

Adserà, A. (2005) Vanishing Children: From high Unemployment to Low Fertility in Developed Countries, American Economic Review Papers and Proceedings 95 (2): 198-193. . (2013) Fertility, Feminism and Faith: How are Secularism and economic Conditions Influencing Fertility in the West? In Eric Kaufman and Bradford Wilcox (eds.)Whither the Child? Causes and Consequences of Low Fertility. p. 1-28. Paradigm Publishers, Colorado 2013.

Adserà, A. and A. Ferrer. (2010). The Fertility Decisions of Canadian Immigrants, In Canadian Research on Immigration. Edited by Arthur Sweetman, Ted McDonald and Elizabeth Ruddick, John Deutchs Institute of Economic Policy, Queen's University. McGillQueen's Press.

. (2011). Speeding up for a son? Fertility transitions among first and second generation migrants to Canada, mimeo, Princeton University.

. (2013a). Fertility Adaptation of Child Migrants to Canada (forthcoming), Population Studies Published online 2013. \#7289. . (2013b). The Fertility of Recent Immigrants to Canada, IZA Working Paper

Adserà, A., A. Ferrer, W. Sigle-Rushton and B. Wilson (2012) "Fertility Patterns of Child Immigrants: Age at Immigration and Ancestry in Comparative Perspective” in The ANNALS of the American Academy of Political and Social Science September, 643(1): 134159. Eds M. Tienda and A. Adserà

Algan, Y., Bisin, A., Manning, A. and Verdier, T. (2012) Cultural Integration of Immigrants in Europe, Studies of Policy Reform. Y. Algan, A. Bisin A. Manning and T. Verdier eds. Oxford University Press, UK.

Algan, Y., Landais, C., \& Senik, C. (2010). “Cultural Integration in France” in Cultural Integration of Immigrants in Europe, Y. Algan, A. Bisin A. Manning and T. Verdier eds. Oxford University Press, UK. pp.49-68

Almond, D. and L. Edlund (2008) "Son-biased sex ratios in the 2000 United states Census,” PNAS 105, no. 15 pp. 5681-5682

Almond, D.; L. Edlund and K. Milligan (2009) "Son Preference and the Persistence of Culture: Evidence from Asian Immigrants to Canada”. NBERWorking Paper 15391

Antecol, H., (2000) "An Examination of Cross-Country Differences in the Gender Gap in Labor Force Participation Rates," Labour Economics, 7(2000): 409-426

Anderson, Gunnar (2004) Childbearing after Migration: Fertility Patterns of Foreign-born Women in Sweden, International Migration Review Volume 38 Issue 2, Pages 747 - 774. 
Avitabile, Ciro, Clots-Figueras, Irma and Masella, Paolo (2014) "Citizenship, Fertility, and Parental Investment”, forthcoming, American Economic Journal: Applied Economics.

Baker, M. and Benjamin, D. (1997) “The Role of the Family in Immigrants’ Labour Market Activity: An Evaluation of Alternative Explanations” American Economic Review 87(4), pp 705-27.

Beck, A., M. Corak and M. Tienda (2012) “Age at Immigration and the Adult Attainments of Child Migrants to the United States" in The ANNALS of the American Academy of Political and Social Science September, 643(1): 134-159. Eds M. Tienda and A. Adserà

Becker, G, (1960) “An Economic Analysis of Fertility.” In Demographic and Economic Change in Developed Countries, NBER conference series 11, Princeton, pp. 209-231. . (1981) A Treatise on the Family. Harvard University Press, Cambridge, Mass.

Bélanger, A. and Gilbert, S. (2003). "The fertility of immigrant women and their Canadian-born daughters”. Report on the demographic situation in Canada 2002, (pp. 91209).

Bean, F., C. Swicegood, and R. Berger. 2000. "Mexican-origin fertility : New patterns and interpretations”. Social Science Quarterly 811): pp. 404-420

Blau, F.D. (1992). The Fertility of Immigrant Women: Evidence from High Fertility Source Countries. In Borjas, G.J. and Freeman, R.B. (eds). Immigration and the Work Force: Economic Consequences for the United States and Source Areas. Chicago: UCP, pp. 93-133.

Blau, F.D., L . Kahn,. A. Yung-Hsu Liu, and K. L. Papps: (2008) “The Transmission of Women's Fertility, Human Capital and Work Orientation Across Immigrant Generations”, NBER working paper \#14388.

Blau, F. D. and L.M. Kahn (2007) "Gender and Assimilation among Mexican Americans,” in George J. Borjas, ed., Mexican Immigration to the United States (Chicago: University of Chicago Press), pp.57-106

Bleakley, H. and A. Chin (2004). "Language Skills and Earnings: Evidence from Childhood Immigrants," The Review of Economics and Statistics, 86(2):481-496.

(2008) What Holds Back the Second Generation? The Intergenerational Transmission of Language Human Capital among Immigrants. Journal of Human Resources. Spring 2008.

(2010) "Age at Arrival, English Proficiency, and social Assimilation among US Immigrants.” American Economic Journal: Applied Economics, vol. 2(1), pp. 165-92.

Bisin, A., \& Patacchini, E. (2012). “Cultural Integration in Italy” in Cultural Integration of Immigrants in Europe, Y. Algan, A. Bisin A. Manning and T. Verdier eds. Oxford University Press, UK. pp.125-147

Borjas, G.J (1985) "Assimilation, Changes in Cohort Quality, and the Earnings of Immigrants," Journal of Labor Economics, vol. 3(4), pages 463-89,

(1987) "Self-Selection and the Earnings of Immigrants." American Economic Review77:531-53. 
----- (1991). "Immigration and Self-Selection." Pp. 29-76 in Immigration, Trade, and the LaborMarket, edited by J.M. Abowd. Chicago: University of Chicago Press

----- (1993) “The Intergenerational Mobility of Immigrants” Journal of Labor Economics, vol. 11(1), pp: 113-35

----- (1999). Heaven's Door: Immigration Policy and the American Economy. Princeton, NJ: Princeton University Press.

Bratter, J. and R. King. (2008) “But Will It Last?': Marital Instability Among Interracial and Same-Race Couples.” Family Relations 57:160-71.

Brown SL, Van Hook J, Glick JE (2008) “Generational Differences in cohabitation and marriage in the U.S.” Population Research and Policy Review; 27(5):531-550

Bumpass, L. and H-H. Lu, (2000) "Trends in cohabitation and implications for children’s family contexts in the US” Population Studies, 54(1): 29-41

Card, D., J. DiNardo and E. Estes, (2000) "The More Things Change: Immigrants and the Children of Immigrants in the 1940s, the 1970s, and the 1990s,” in George J. Borjas, ed., Issues in the Economics of Immigration (Chicago: University of Chicago Press), pp. 227-269.

Carlson, E. (1985) “Increased nonmarital births among foreign women in Germany”, Sociology and Social Research 70(1): 110-111

Carter, M.. 2000. Fertility of Mexican Immigrant Women in the U.S.: a closer look, Social Science Quarterly 81(1): 404-420

Castro M. T. (2002). “Consensual unions in Latin America: Persistence of a dual nuptiality system. Journal of Comparative Family Studies, 33, 35 - 55

Celikaksoy, A., H. Nielsen and M. Verner (2006). "Marriage Migration: Just Another Case of Positive Assortative Matching?”, Review of Economics of the Household, vol.4 pp. 253275

Chiswick BR (1978) The Effect of Americanization on the Earnings of ForeignBorn Men. Journal of Political Economy 86(5): 897-922.

--------- (1991). "Speaking, Reading, and Earnings among Low-Skilled Immigrants”, Journal of Labor Economics, Vol. 9, No. 2 pp. 149-170

Chiswick, B.R. and P. Miller (1995) The Endogeneity between Language and Earnings: International Analyses, Journal of Labor Economics 13:2, p. 246-288.

(2001) "A model of destination-language acquisition: Application to male immigrants in Canada," Demography, vol. 38(3), pages 391-409.

Chiswick, C. U., and E. Lehrer. (1991) "Religious intermarriage: An economic perspective." Contemporary Jewry 12.1: 21-34.

Choi, K. (2014) "Fertility in the Context of Mexican Migration to the United States" forthcoming Demographic Research

Choi, Kate H., Marta Tienda, Deborah Cobb-Clark, and Mathias Sinning (2012) "Immigration and Status Exchange in Australia and the United States", Research in Social Stratification and Mobility. 30(1): 49-62. 
Coleman, D. (2006). "Immigration and Ethnic Change in Low-Fertility Countries, a Third Demographic Transition”, Population and Development Review 32(3): 401446.

Coleman D, Compton P and Salt J (2002) Demography of migrant populations: the case of the United Kingdom (pp.497-552), in Haug W, Compton P and Courbage Y (eds.), The Demographic Characteristics of Immigrant Populations (Population Studies No. 38), Council of Europe, Strasbourg.

Coleman D. and S. Dubuc (2010) "The fertility of ethnic minority populations in the United Kingdom, 1960s - 2006”, Population Studies, 64(1): 19-41

Constant, A., Nottmeyer, O., \& Zimmermann, K. (2010). “Cultural Integration in Germany” in Cultural Integration of Immigrants in Europe, Y. Algan, A. Bisin A. Manning and T. Verdier eds. Oxford University Press, UK. pp.69-124

Courgeau, D. 1989. Family formation and urbanization, Population: An English Selection 44(1): 123-146.

Clark, K., \& Lindley, J. (2009). Immigrant assimilation pre and post labour market entry: Evidence from the UK labour force survey. Journal of Population Economics, 22(1), 175-198

De la Rica, S. and F. Ortega (2010). “Cultural Integration in Spain” in Cultural Integration of Immigrants in Europe, Y. Algan, A. Bisin A. Manning and T. Verdier eds. Oxford University Press, UK. pp.148-171

Dubuc, Sylvie (2009) Application of the own-children method for estimating fertility by ethnic and religious groups in the UK. Journal of population research. 26 (3), pp. 207-225 New York, NY: Springer.

. (2012). Immigration to the UK from High-Fertility Countries: Intergenerational Adaptation and Fertility Convergence. Population and Development Review, 38: 353-368.

Dubuc, S. and D. Coleman. (2007) An increase in the sex ratio of births to India-born mothers in England and Wales: Evidence for sex-selective abortion. Population and Development Review, 33(2):383-400, June.

Duncan, B. and S. Trejo (2007) Ethnic Identification, Intermarriage and Unmeasured Progress by Mexican Americans. In G. J. Borjas ed. Mexican Immigration to the United States, Chicago, National Bureau of Economic research and the University of Chicago Press, p. 229-267.

Dribe, M., C. Lundh (2011) Cultural Dissimilarity and Intermarriage. A Longitudinal Study of Immigrants in Sweden 1990-2005, International Migration Review, vol. 45(2), pp. 297-324

Feliciano, C. (2005). Educational selectivity in U.S. immigration: How do immigrants compare to those left behind? Demography, 42, 131-152.

Fernandez, R. and A. Fogli (2006) Fertility: The Role of Culture and Family Experience, Journal of the European Economic Association

(2009) "Culture: An Empirical Investigation of Beliefs, Work, and Fertility." American Economic Journal: Macroeconomics 1,1 (January 2009): 146-177 
Ferrer, A. and W.C. Riddell (2008.) "Education, credentials, and immigrant earnings" Canadian Journal of Economics, vol. 41(1), pages 186-216,

Ford, K. (1990) "Duration of Residence in the United States and the Fertility of U.S. Immigrants" International Migration Review, Vol. 24 (1): 34-68.

Forste, Renata, and Tienda, Marta. (1996). What's Behind Racial and Ethnic Fertility Differentials? Population and Development Review, 22(S): 109-133

Frank, R., and Heuveline, P. (2005). A crossover in Mexican and Mexican-American fertility rates: Evidence and explanations for an emerging paradox. Demographic Research, 12, $77-104$.

Fu, V. K., and N. Wolfinger (2011) "Broken Boundaries or Broken Marriages? Racial Intermarriage and Divorce in the United States”, Social Science Quarterly vol. 92(4) pp. 10961117.

Furtado, D. (2012), Human Capital and Interethnic marriage decisions, Economic Inquiry, Vol. 50(1), pp. 82 - 93.

Furtado, D. and N. Theodoropoulos (2011) Interethnic marriage: a choice between ethnic and educational similarities, Journal of Population Economics v ol .24:1257-1279

Furtado, D and S. Trejo (2013) Interethnic Marriages and their Economic Effects (published in: Amelie F. Constant and Klaus F. Zimmermann (eds.), International Handbook on the Economics of Migration, Edward Elgar 2013, Cheltenham, UK, and Northampton, USA, Chapter 15, 276-292)

Galor, O. and D. Weil. (1996). “The Gender Gap, Fertility and Growth.” American Economic Review 86: 374-387.

Georgiadis, A. and A. Manning (2011) Change and Continuity Among Minority Communities in Britain , Journal of Population Economics 24:541-568.

Georgiadis, A. and A. Manning (2010) “Cultural Integration in the United Kingdom” in Cultural Integration of Immigrants in Europe, Y. Algan, A. Bisin A. Manning and T. Verdier eds. Oxford University Press, UK. pp.260-284

Gjerde, Jon, and Anne McCants (1995) Fertility, Marriage and culture: Demographic processes among Norwegian Immigrants to the Rural Middle West, Journal of Economic History, 55 (4): 860-88.

Goldstein, S. \& Goldstein, A. (1981) The Impact of Migration on Fertility: an `Own Children' Analysis for Thailand. Population Studies, 35, 265-284.

(1983) “Migration and Fertility in Peninsular Malaysia: An Analysis Using Life History Data” Santa Monica, CA: RAND Corporation

Gonzalez-Ferrer, A. (2006) "Who do Immigrant Marry? Partner Choice Among Single Immigrants in Germany” European Sociological Review, vo. 22(2), pp. 171-185

Guinnane, Timothy W. \& Moehling, Carolyn M. \& O Grada, Cormac, (2006). "The Fertility of the Irish in America in 1910," Explorations in Economic History 43 (3): 465-85.

Heran, F. and G. Pison (2007) "Two Children per women in France in 2006: Are 
immigrants to blame?” Fertility among immigrant women: new data, a new approach”, Population \& Societies, no. 432, 2004

Hervitz, H. M. (1985) Selectivity, Adaptation, or Disruption? A Comparison of Alternative Hypotheses on the Effects of Migration on Fertility: The Case of Brazil. International Migration Review, 19, 293-317.

Huschek, D, A. Liefbroer and H. de Valk (2010) “Timing of first union among second-generation Turks in Europe: The role of parents, peers and institutional context”, Demographic Research vol.22, article 16

Jacobs, J. A., and Furstenberg, F. F., Jr. (1986). “Changing places: Conjugal careers and women’s marital mobility,” Social Forces 64, 714-732.

Jasso, G. and Rosenzweig, M.R. (1990) The Immigrant's Legacy: Investing in the Next Generation. In Jasso, G. and Rosenzweig. M.R. (eds) The New Chosen People: Immigrants in the United States. Russell Sage Foundation, NY, pp.382-410

Jasso, G., D. S. Massey, M.R. Rosenzweig and J. P. Smith (2000) Assortative Mating among Married New Legal Immigrants to the United States: Evidence from the New Immigrant Survey Pilot, International Migration Review, Vol. 34(2), pp. 443-459

Jensen, E. and D. Ahlburg (2004) “Why does migration decrease fertility? Evidence from the Philippines?” Population Studies vol 58 (2), pp.219-31

Kahn, J. (1988) Immigrant Selectivity and Fertility Adaptation in the United States. Social Forces, Vol. 67.

(1994) Immigrant and Native Fertility during the 1980s: Adaptation and Expectations for the Future, International Migration Review 28 (2): 501-519.

Kalbach,W. (1970) “The Impact of Immigration on Canada's Population”. Queen's Printer, Ottawa.

Kalmijn, M. (1998). Intermarriage and Homogamy: Causes, Patterns and Trends. Annual Review of Sociology, 24, 395-421.

Kalmijn, M., A. Loeve and D. Manting (2007) "Income Dynamics in Couples and the Dissolution of Marriage and Cohabitation” Demography, Vol. 44, No. 1, pp. 159-179

Kalmijn, Matthijs, Paul M. de Graaf, and Jacques Janssen. (2005) “Intermarriage and the Risk of Divorce in the Netherlands.” Population Studies 59:71-85.

Kane, T. T. (1986) “The fertility and assimilation of guestworker populations in the Federal Republic of Germany: 1961-1981.” Zeitschrift für Bevölkerungswissenschaft 12(1): 99-131.

Kantarevic, Jasmin (2004) Interethnic Marriages and Economic Assimilation of Immigrants (May 2004). IZA Discussion Paper No. 1142.

Klasen, S. and C. Wink, (2003) "Missing Women: Revisiting the Debate", (2003), Feminist Economics 9 (2-3): 263-299.

Kulu, H. (2005). "Migration and Fertility, Competing Hypotheses Re-examined." European Journal of Population 21: 51-87. 
- (2006) "Fertility of internal migrants: comparison between Austria and Poland" Population, Space and Place 12(3): 147-170

Lanzieri, Giampaolo (2012) Merging populations: A look at marriages with foreign-born persons in European countries, Statistics in focus 29/2012, Eurostat, Luxembourg

Lee, S. M. and M. Boyd (2008) Marrying out: Comparing the marital and social integration of Asians in the US and Canada, Social Science Research, Volume 37(1), pages 311-329

Lehrer, E. (2003) The Economics of Divorce,” Pp. 55-74 in Shoshana-Shechtman (ed.) Marriage and the Economy: Theory and Evidence from Industrialized Societies. Cambridge: Cambridge University Press.

Lehrer, Evelyn L. and Carmel U. Chiswick. (1993). "Religion as a Determinant of Marital Stability.” Demography 30 (3): 385-404.

Lesthaeghe, R. J., \& Neidert, L. (2006). The second demographic transition in the United States: Exception or textbook example? Population and Development Review, 32, 669-687

Liang, Z. and N. Ito (1999) "Intermarriage of Asian-Americans in the New York City Region: Contemporary Patterns and Future Prospects”, International Migration Review, 33(4): 876-900

Lievens, J. (1998). Interethnic Marriage: Bringing in the Context through Multilevel Modelling. European Journal of Population, 14, 117-155.

Lievens, J. (1999). Family-formation Migration from Turkey and Morocco to Belgium: The Demand for Marriage Partners from the Countries of Origin. International Migration Review, 33, 717-744.

Lhila, A. and S. Kosali (2008). “Prenatal health investment decisions: Does the child’s sex matter?” Demography , 45( 4): 885-905,

Lindstrom, D. P. (2003). Rural-urban migration and reproductive behaviour in Guatemala, Population Research and Policy Review 22(4): 351-372.

Lundberg, S. and R. A. Pollak (1993). "Separate Spheres Bargaining and the Marriage Market”, Journal of Political Economy, 101(6), pp. 988-1010

Mayer, J. and Riphahn, R. (2000) "Fertility assimilation of immigrants: Evidence from count data models” Journal of Population Economics, 13(2), 241-261.

Milewski, N. (2007). "First child of immigrant workers and their descendants in West Germany: Interrelation of events, disruption, or adaptation?” Demographic Research 17(29): 859-896.

Milewski, N. and Hamel, C. (2010). "Union formation and partner choice in a transnational context: The case of descendants of Turkish migrants in France" International Migration Review, 44(3), pp. 615-58

Meng, X. and Gregory, R. (2005) "Intermarriage and the Economic Assimilation of Immigrants” Journal of Labor Economics 23(1) pp.135-75.

Milan, Anne, Hélène Maheux and Tina Chui (2010) A portrait of couples in mixed unions, Canadian Social Trends, Catalogue no. 11-008, Statistics Canada 
Mulder, C.H. and Wagner, M. (1993). Migration and marriage in the life course: A method for studying synchronized events. European Journal of Population 9(1): 55-76.

Niedomysl, T., J. Östh and M. van Ham (2010) "The Globalisation of Marriage Fields: The Swedish Case”, Journal of Ethnic and Migration Studies, Vol. 36(7), pp. 1119-1138

Nielsen, H., N. Smith and A. Celikaksoy (2009) "The Effect of Marriage on Education of Immigrants: Evidence from a Policy Reform Restricting Marriage Migration" Scandinavian Journal of Economics, 111(3), pp.457-486.

Ng, E. and Nault, F. (1997) “Fertility among Recent Immigrant Women to Canada, 1991: An Examination of the Disruption Hypothesis”, International Migration 35 (4), 559-580.

Pabilonia, S. and J. Ward-Batts (2007) “The Effect of Child Gender on Parents' Labor Supply: An Examination of Natives, Immigrants, and their Children”, The American Economic Review , Vol. 97(2), pp. 402-406

Pagnini, D. L. and Morgan, P. (1990). Intermarriage and Social Distance among US Immigrants at the Turn of the Century. American Journal of Sociology, 96, 405-432.

Parrado, E. A (2011) "How High is Hispanic/Mexican Fertility in the United States? Immigration and Tempo Considerations”, Demography, vol. 48(3), pp.1059-80

Parrado, E. A. and S. P. Morgan (2008) "Intergenerational Fertility Among Hispanic Women: New Evidence of Immigrant Assimilation." Demography 45

Parrado, E. A., and Flippen, C. A. (2005). Migration and gender among Mexican women, American Sociological Review, 70, 606-632

Passel, Jeffrey. S., Wendy Wang and Paul Taylor (2010) Marrying Out: One-in-Seven New U.S. Marriages is Interracial or Interethnic, Social and Demographic Trends Report, Pew Research Center.

Phillips, J., \& Sweeney, M. M. (2006). Can differential exposure to risk factors explain recent racial and ethnic variation in marital disruption? Social Science Research, 35, 409434.

Picot, G. , F. Hou and S. Coulombe (2007) “Chronic Low Income and Low-income Dynamics Among Recent Immigrants”, Analytical Studies Branch Research Paper Series, No. 294. Satatistics Canada.

Qian, Z. (2013) Divergent Paths of American Families, US2010 Project. Report sponsored by Russell Sage Foundation and American Communities Project of Brown University

Qian, Z., J. Glick and C. Batson (2012). Crossing Boundaries: Nativity, Ethnicity, and Mate Selection. Demography, 49(2), 651-675.

Qian, Z., and D. T. Lichter (2007). Social boundaries and marital assimilation: Interpreting trends in racial and ethnic intermarriage. American Sociological Review, 72, 68 94.

Qian, Z. and D. Lichter (2001) Measuring Marital Assimilation: Intermarriage among Natives and Immigrants, Social Science Research, Volume 30, Issue 2, pp. 289-312, 
Ralston, H. (1999), "Canadian Immigration Policy in the Twentieth Century. Its Impact on South Asian Women” Canadian Women Studies vol.19(35), pp.33-37

Ram, Bali and M.V. George, (1990) Immigrant fertility patterns in Canada, 1961-1986. International Migration 28(4): 413-426.

Rindfuss, Ronald R. (1976) "Fertility and Migration: The Case of Puerto Rico." International Migration Review 10:191-203.

Rosenfeld, M. (2002). Measures of Assimilation in the Marriage Market: Mexican Americans 1970-1990. Journal of Marriage and the Family, 64, 152-162.

Rosenwaike, Ira. (1973). Two Generations of Italians in America: Their Fertility Experience, International Migration Review, Vol. 7, No. 3 (Autumn), pp. 271-280

Rumbaut, R. (1997) "Ties that Bind Immigration and Immigrant Families." Immigration and the family: Research and policy on US immigrants pp. 3-46.

Ryder, Norman B. (1973). "A Critique of the National Fertility Study." Demography 10:495-506.

Schaafsma, J and A. Sweetman (2001). "Immigrant Earnings: Age at Immigration Matters”, The Canadian Journal of Economics, 34 (4), pp. 1066-1099

Schoorl, J.J. (1990) "Fertility adaptation of Turkish and Moroccan women in the Netherlands” International Migration 28(4): 477-95

Schoorl, J.J. (1995) “Fertility trends of Immigrant Population” in : Voets, S., Schoorl, J. and de Brujin, B. (eds). Demographic Consequences of International Migration, pp. 97-121. Rapport no 44. The Hague: NIDI

Sigle-Rushton, W. (2008). "England and Wales: Stable Fertility and Pronounced Social Status Differences.” Demographic Research 19: 459-502.

Singley, S. and N. Landale (1998) "Incorporating Origin and Process in MigrationFertility Frameworks: The Case of Puerto Rican Women." Social Forces 76(4): 14371464.

Smith, J.P. (2003). “Assimilation across the Latino Generations”, American Economic Review, 93(2). Pp.315-19.

Sobotka, T. (2008). “The rising importance of migrants for childbearing in Europe.” Demographic Research 19(9): 225-248.

Sorenson, A.M. (1988) “The Fertility and Language Characteristics of Mexican-American and Non-Hispanic Husbands and Wives” The Sociological Quarterly, 29(1): 111-130

Stephen, E.H. and F.D. Bean. (1992) "Assimilation, disruption and fertility of Mexican-origin women in the United States." International Migration Review 26(1):6788.

Stevenson, Betsey and Justin Wolfers (2007). "Marriage and Divorce: Changes and their Driving Forces," Journal of Economic Perspectives, vol. 21(2): 27-52, Spring.

Sweetman, A. and Jan C. Van Ours (2014) Immigration: What about the 
Children and Grandchildren? In Chiswick, B.R. and P.W. Miller (Eds.), Handbook of the Economics of International Migration, Vol. 1, Amsterdam: Elsevier

Toulemon, L. (2004). "Fertility among immigrant women, new data, a new approach.” Population \& Societies 400 (April 2004): 1-4.

Toulemon, L., A. Paihle, C.Rossier (2008) France: High and stable fertility, Demographic Research, vol. 19, article 16, pp. 503-556

Trilla, C., A. Esteve, A. and A. Domingo (2008) "Marriage Patterns of the Foreign-Born Population in a New Country of Immigration: The Case of Spain”, International Migration Review, Vol. 42, No 4, pp: 877-902

United Nations (2001). Replacement Migration, is it a solution to declining and ageing population?. New York: United Nations Population Division. Sales No. E01.XIII.19

Vasileva, K. (2011), ‘Population and Social Conditions”, Statistics in Focus, 34/2011, Eurostat

Westoff, C.F. and Frejka, T. 2007. Religiousness and Fertility Among European Muslims. Population and Development Review. 33.

Westoff, C.F., and Frejka, T. Religion, Religiousness and Fertility in the United States and in Europe. European Journal of Population. 24. 2008

White, M. L. Moreno and S. Guo, 1995. “The Interrelationship of Fertility and Geographic Mobility in Peru: A Hazard Model Analysis” International Migration Review 29(2):492-515

Willis, R. (1974) "Economic Theory of Fertility Behavior.” In Economics of the Family: Marriage, children and Human Capital, Schultz ed. UMI, NBER pp.25-80

Worswick, C.(1996) “Immigrant Families in the Canadian Labor Market” Canadian Public Policy 22(4): 378-96.

Zhang, Y. and J. Van Hook (2009) "Marital Dissolution Among Interracial Couples”, Journal of Marriage and Family vol. 71(1) pp. 95- 107. 
Table 1 Immigration and intermarriage in main host countries in 2010 (in 1000s)

\begin{tabular}{lccccc} 
Country & $\begin{array}{c}\text { Total } \\
\text { population }\end{array}$ & $\begin{array}{c}\text { Total } \\
\text { Foreign-born }\end{array}$ & $\begin{array}{c}\text { Mixed Marriages } \\
\text { (2008-10)(a) }\end{array}$ \\
\hline EU 27 & & & & $\begin{array}{c}\text { \% Native } \\
\text { \%orn }\end{array}$ & $\begin{array}{c}\text { Foreign } \\
\text { Born }\end{array}$ \\
Germany & 501,098 & 47,348 & 9.4 & -- & -- \\
France & 81,802 & 9,812 & 12.0 & 6.8 & 28.5 \\
UK & 64,716 & 7,196 & 11.1 & 7.0 & 37.0 \\
Spain & 62,008 & 7,012 & 11.3 & 5.1 & 31.1 \\
Netherlands & 16,575 & 1,832 & 11.1 & 5.1 & 39.6 \\
Greece & 11,305 & 1,256 & 11.1 & 1.6 & 17.1 \\
Sweden & 9,340 & 1,337 & 14.3 & 5.4 & 34.4 \\
Austria & 8,367 & 1,276 & 15.2 & 6.6 & 27.1 \\
Belgium (b) & 10,666 & 1,380 & 12.9 & 6.5 & 36.2 \\
US & 269,394 & 39,956 & 12.9 & 4.4 & 27.9 \\
Canada (b) & 34,484 & 7,472 & 21.7 & -- & -- \\
Australia & 22,183 & 6,000 & 27.0 & & 31.3 \\
\hline
\end{tabular}

Source: Statistics Canada; US Census Bureau; Australian Census Bureau. European data comes from Vasileva (2011). Total population and foreign-born population are expressed in thousands of individuals.

(a) Lanzieri (2012) for European countries; Marriages and Divorces, Australia, 2010 in Australian Bureau of Statistics (2011); American Community Survey (ACS) 2011 for US.

(b) Data on immigrants for Belgium is for 2007 and for Canada for 2011. 
Table 2: Share of births and total fertility rates (TFR) of natives and immigrants.

\begin{tabular}{|c|c|c|c|c|c|c|}
\hline \multirow[t]{2}{*}{ Country } & \multirow[t]{2}{*}{ Period } & \multicolumn{2}{|c|}{ \% Births } & \multicolumn{2}{|c|}{$\operatorname{TFR}^{\text {(a) }}$} & \multirow[t]{2}{*}{ Source } \\
\hline & & Migrants & Nationals & Native & Immigrant & \\
\hline \multirow[t]{2}{*}{ Austria } & 2000 & & 13.5 & 1.29 & 2.03 & Kytir 2006 \\
\hline & 2005 & & 11.7 & & & Kytir 2006 \\
\hline \multirow[t]{2}{*}{$\begin{array}{l}\text { Belgium } \\
\text { (Flanders) }\end{array}$} & 2003-04 & 16.81 & 12.4 & & & VAZG 2007 \\
\hline & 2001-05 & & & 1.50 & 3.00 & \\
\hline \multicolumn{7}{|c|}{2.45 seatistics Detillialk 2004} \\
\hline \multirow[t]{5}{*}{ Wales } & 1980 & 13.3 & & & & Schoorl 1995 \\
\hline & 1995 & 12.6 & & & & ONS 2006 \\
\hline & 2001 & & & 1.6 & 2.2 & ONS 2006 \\
\hline & 2005 & 20.8 & & & & ONS 2006 \\
\hline & 2006 & 21.9 & & & & ONS 2007 \\
\hline \multirow[t]{2}{*}{ France } & 1991-98 & 12.4 & & 1.65 & 2.5 & $\begin{array}{l}\text { Toulemon } 2004 \\
\text { Prioux 2005; Heran and Pison }\end{array}$ \\
\hline & 2004 & 15 & 12.4 & 1.8 & 3.29 & 2007 \\
\hline \multirow[t]{4}{*}{ Germany } & 1980 & & 15 & & & Schoorl 1995 \\
\hline & 1985 & & 11.2 & & & Schoorl 1995 \\
\hline & 1995 & & 16.2 & & & Statistisches Bundesamt 2006 \\
\hline & 2004 & & 17.6 & & & Statistisches Bundesamt 2006 \\
\hline \multirow[t]{3}{*}{ Italy } & 1999 & & 5.4 & & & ISTAT 2007 \\
\hline & 2004 & & 11.3 & 1.26 & 2.61 & ISTAT 2006, 2007 \\
\hline & 2005 & & 12.2 & & & ISTAT 2007 \\
\hline \multirow[t]{2}{*}{ Netherlands } & 1996 & 15.5 & & & & CBS Statline 2006 \\
\hline & 2005 & 17.8 & & 1.65 & 1.97 & CBS Statline 2006 \\
\hline \multirow[t]{4}{*}{ Spain } & 1996 & & 3.3 & & & INE 2006 \& 2007 \\
\hline & 2000 & & 6.2 & 1.19 & 2.12 & \\
\hline & 2004 & & 13.7 & & & \\
\hline & 2006 & & 16.5 & 1.32 & 1.64 & Roig Vila and Castro Martin 2007 \\
\hline Sweden & 2005 & 19.5 & 11.8 & 1.72 & 2.01 & Statistics Sweden 2006 \\
\hline \multirow[t]{4}{*}{ Switzerland } & 1980 & & 15.3 & & & Coleman 2003 \\
\hline & 1997 & & & 1.34 & 1.86 & Wanner 2002 \\
\hline & 2000 & & 22.3 & & & Coleman 2003 \\
\hline & 2005 & & 26.3 & & & SFSO 2006 \\
\hline
\end{tabular}

Source: Data compiled from Tables 1 and 2 a \& b in Sobotka (2008)

(a) TFR data is for Native nationals (instead of natives) and foreign nationals (instead of immigrants) in Austria, Flanders, France in 2004, Italy, Spain and Switzerland. 
Table 4: Spousal or partner racial/ethnic composition by Gender, ethnicity and age at arrival, ages 2034, 2000 PUMS, USA

\begin{tabular}{|c|c|c|c|c|c|c|c|c|}
\hline & \multicolumn{4}{|c|}{$\%$ Males Married or cohabiting with } & \multicolumn{4}{|c|}{$\%$ Females Married or cohabiting with } \\
\hline & Coethnic & $\begin{array}{l}\text { Inter- } \\
\text { ethnic }\end{array}$ & White & Other & Coethnic & $\begin{array}{l}\text { Inter- } \\
\text { ethnic }\end{array}$ & White & Other \\
\hline \multicolumn{9}{|l|}{ Ethnicity/Age } \\
\hline \multicolumn{9}{|l|}{ Chinese } \\
\hline $\begin{array}{l}\text { Arriving at ages } \\
14-19\end{array}$ & 86.2 & 8.2 & 3.6 & 2.1 & 76.2 & 7.2 & 13.5 & 3.2 \\
\hline $\begin{array}{l}\text { Arriving at ages } \\
6-13\end{array}$ & 68.4 & 15 & 14 & 2.6 & 59.2 & 15.1 & 20.4 & 5.3 \\
\hline $\begin{array}{l}\text { Arriving at ages } \\
0-5\end{array}$ & 48.9 & 9 & 33.1 & 9 & 46.1 & 8.9 & 39.4 & 5.6 \\
\hline U.S.-born & 41.5 & 16.9 & 34.8 & 6.9 & 28.6 & 11.8 & 51.4 & 8.3 \\
\hline \multicolumn{9}{|l|}{ Filipino } \\
\hline $\begin{array}{l}\text { Arriving at ages } \\
14-19\end{array}$ & 75.7 & 3.3 & 14.5 & 6.5 & 51.7 & 4.8 & 30.5 & 13 \\
\hline $\begin{array}{l}\text { Arriving at ages } \\
6-13\end{array}$ & 57.2 & 5.9 & 26.1 & 10.8 & 42.7 & 7.1 & 33 & 17.2 \\
\hline $\begin{array}{l}\text { Arriving at ages } \\
0-5\end{array}$ & 37 & 6.3 & 42.2 & 14.6 & 23.2 & 4.1 & 56.4 & 16.4 \\
\hline U.S.-born & 29 & 8.7 & 48.7 & 13.6 & 20.8 & 8 & 53.6 & 17.6 \\
\hline \multicolumn{9}{|l|}{ Mexican } \\
\hline $\begin{array}{l}\text { Arriving at ages } \\
14-19\end{array}$ & 90.2 & 4.2 & 5 & 0.6 & 94.5 & 3.3 & 1.8 & 0.4 \\
\hline $\begin{array}{l}\text { Arriving at ages } \\
6-13\end{array}$ & 88.2 & 4.6 & 6.1 & 1.1 & 90.1 & 4.2 & 4.5 & 1.3 \\
\hline $\begin{array}{l}\text { Arriving at ages } \\
0-5\end{array}$ & 81.1 & 5.4 & 12 & 1.5 & 82.4 & 5.2 & 10 & 2.4 \\
\hline U.S.-born & 64.4 & 3.6 & 29.2 & 2.8 & 67.1 & 3.6 & 25.4 & 3.9 \\
\hline
\end{tabular}

Source: Excerpts from Table 2 in Qian, Z., J. Glick and C. Batson (2012). 
Figure 1: Mechanism of Immigrant Fertility

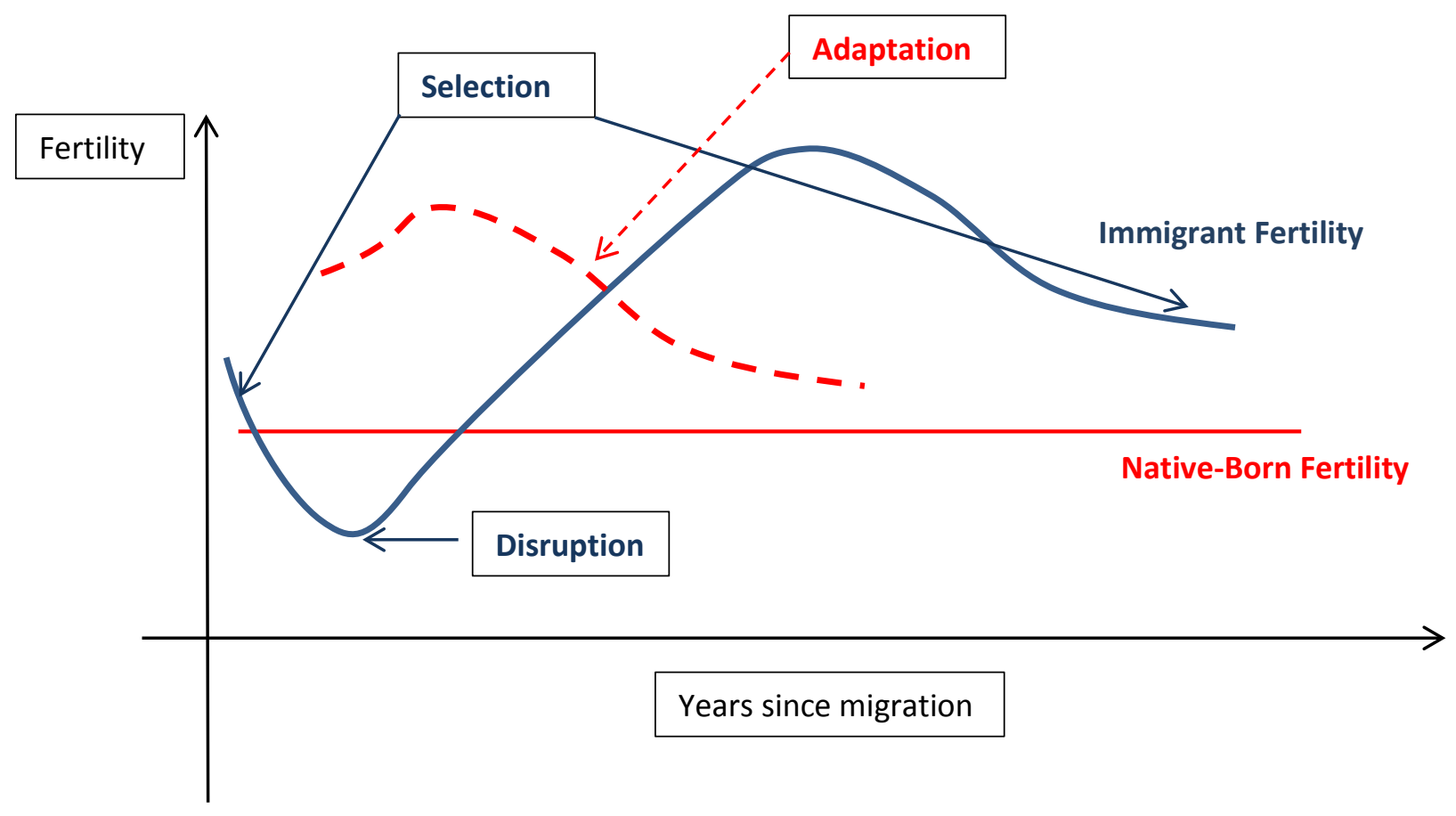


Figure 2: Incidence Rate Ratios (IRRs) from a Poisson regression of the number of children in the household of women who migrated as children by age at immigration relative to native born women, in England \& Wales, France and Canada.

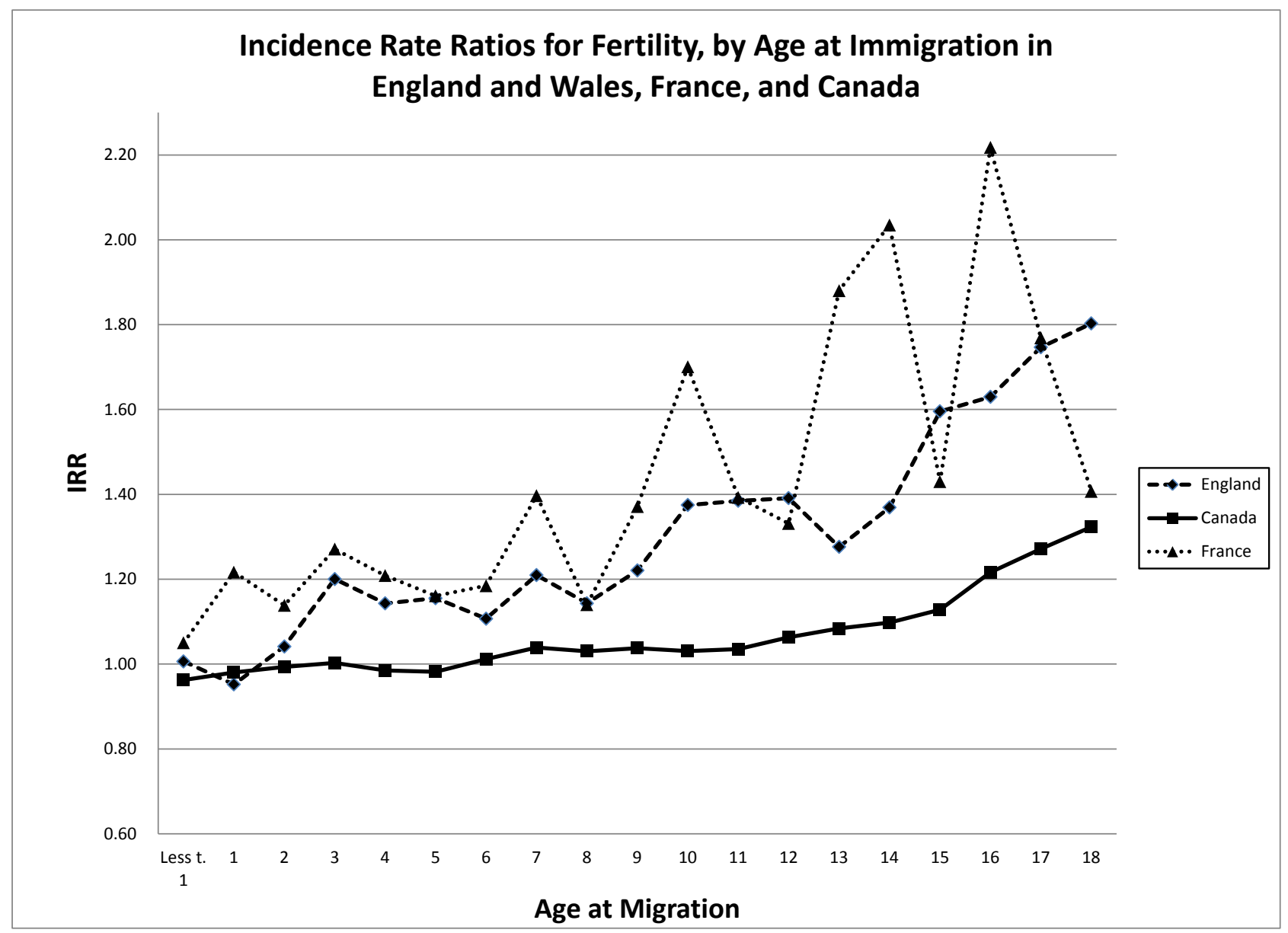

Note: All models include controls for age, location of residence and census year.

Source: Estimates from Adserà et al. (2012). Data from Canada comes from the Canadian Census 1991, 1996, 2001 and 2006. The data for England are a subsample of the Office for National Statistics Longitudinal Study (ONSLS), a complete set of linked census records (1971-2001) and that for France come from "Enquête sur Trajectoires et Origines" (TeO) 2008. 
Table 3. Summary of Main References on Marriage

\begin{tabular}{|c|c|c|c|c|c|c|c|}
\hline & $\begin{array}{c}\text { Year / } \\
\text { Country }\end{array}$ & Sample & Intermarriage & Marriage Market & Assimilation & Characteristics & Results \\
\hline \multicolumn{8}{|c|}{ Determinants of intermarriage } \\
\hline $\begin{array}{l}\text { Dribe and } \\
\text { Lundh (2011) }\end{array}$ & $\begin{array}{l}2003 \\
\text { Sweden }\end{array}$ & $\begin{array}{l}\text { Immigrants 20-59, } \\
\text { married in Sweden } \\
\text { after } 1968 .\end{array}$ & $\begin{array}{l}2 \text { types of exogamy, } \\
\text { relative to marrying } \\
\text { immigrant in same } \\
\text { ethnic group }\end{array}$ & $\begin{array}{l}\text { Size of the opposite } \\
\text { sex group at } \\
\text { settlement level }\end{array}$ & $\begin{array}{l}\text { Age at } \\
\text { immigration, time } \\
\text { between } \\
\text { immigration and } \\
\text { marriage, CO }\end{array}$ & $\begin{array}{l}\text { Education, age, } \\
\text { race, gender }\end{array}$ & $\begin{array}{l}\text { Exogamy associated with being } \\
\text { younger, more time btw migration and } \\
\text { marriage, education (except for Asian } \\
\text { women) and older age at immigration. } \\
\text { Indirect evidence of assortative } \\
\text { matching on education }\end{array}$ \\
\hline $\begin{array}{l}\text { Chiswick and } \\
\text { Houseworth } \\
\text { (2011) }\end{array}$ & $\begin{array}{l}1980 \\
\text { US }\end{array}$ & $\begin{array}{l}\text { Immigrants married } \\
\text { after migration and } \\
\text { currently married }\end{array}$ & $\begin{array}{l}\text { Exogamous = } \\
\text { married to a } \\
\text { different ethnicity } \\
\text { (by ancestry or } \\
\text { country of birth) }\end{array}$ & $\begin{array}{l}\text { Individuals of } \\
\text { marriageable age in } \\
\text { the SMSAs (or State), } \\
\text { number of opp. sex in } \\
\text { the ethnicity group } \\
\text { and MMkt, total } \\
\text { population by region } \\
\text { and age group }\end{array}$ & $\begin{array}{l}\text { Years since } \\
\text { migration, age at } \\
\text { immigration and } \\
\text { linguistic } \\
\text { distance }\end{array}$ & $\begin{array}{l}\text { veteran, race, } \\
\text { gender, times } \\
\text { married, education, } \\
\text { deviations from } \\
\text { mode education of } \\
\text { the group, multiple } \\
\text { ancestry }\end{array}$ & $\begin{array}{l}\text { Exogamy associated with being } \\
\text { younger, time btw immigration and } \\
\text { marriage, education (except for Asian } \\
\text { women) and older age at immigration } \\
\text { (but more likely to marry within } \\
\text { ancestry). } \\
\text { Linguistic distance has a strong effect } \\
\text { on intermarriage (except for Korean } \\
\text { and Japanese speaking women) } \\
\text { Evidence of assortative matching }\end{array}$ \\
\hline $\begin{array}{l}\text { Kalmijn and } \\
\text { Van Tubergen, } \\
\text { (2010) }\end{array}$ & $\begin{array}{l}1994- \\
2006 \\
\text { US }\end{array}$ & $\begin{array}{l}\text { Children of } \\
\text { immigrants or } \\
\text { immigrating }<16\end{array}$ & $\begin{array}{l}\text { Married to NB, } \\
\text { married to a 1st or } \\
\text { 2nd G of the same } \\
\text { CO, married a 1st or } \\
\text { second G of other } \\
\text { CO (by mother or } \\
\text { father ancestry) }\end{array}$ & $\begin{array}{l}\text { State level, linguistic } \\
\text { similarity of other } \\
\text { groups in the state, } \\
\text { religious similarity to } \\
\text { other groups in the } \\
\text { state, group size in the } \\
\text { state, group sex ratio, }\end{array}$ & $\begin{array}{l}\text { Early marriage } \\
\text { customs, } \\
\text { Christian } \\
\text { background, } \\
\text { non-English CO }\end{array}$ & $\begin{array}{l}\text { Generational status, } \\
\text { race, education, age, } \\
\text { cohabitation, } \\
\text { education deviations } \\
\text { from group, ethnic } \\
\text { diversity index }\end{array}$ & $\begin{array}{l}\text { Strong cultural backgrounds (non- } \\
\text { Christian religion, non-English CO, } \\
\text { early marriage in country of origin) } \\
\text { increase endogamy. No effect of sex } \\
\text { ratios } \\
\text { Positive assortative matching }\end{array}$ \\
\hline $\begin{array}{l}\text { Georgiadis } \\
\text { and Manning } \\
(2010)\end{array}$ & $\begin{array}{l}\text { 2000-08 } \\
\text { UK }\end{array}$ & $\begin{array}{l}\text { Married immigrants } \\
\text { and NB, White, } \\
\text { Indian, Pakistani, } \\
\text { Bangladeshi, Black } \\
\text { Caribbean, Black } \\
\text { African, Chinese, }\end{array}$ & $\begin{array}{l}\text { Married to someone } \\
\text { from the CO who } \\
\text { came as an adult }\end{array}$ & NONE & $\begin{array}{l}\text { Generational } \\
\text { status }\end{array}$ & Age, education & $\begin{array}{l}\text { Higher intermarriage among second } \\
\text { generation. Chinese immigrant } \\
\text { women and Black immigrants more } \\
\text { likely to intermarry. }\end{array}$ \\
\hline
\end{tabular}




$\begin{array}{lll}\text { Lee and Boyd, } & 2000 & \text { Reported single } \\ \text { (2008) } & \text { Canada } & \begin{array}{l}\text { Asian origin and their } \\ \text { spouses }\end{array}\end{array}$

Endogamous $=$ married to same race or intermarried to other race generational

status
Residence, age, education, income, ethnic group,
In both countries, Asian women more likely to intermarriage. Among these, the younger and more educated more likely to intermarry. Overall intermarriage rates higher in US

age at marriage,

marriage order;

Endogamy = Municipality. Group

immigrant married

to $\mathrm{FB}$ spouse of the

same CO size and sex ratio; dissimilarity index

(relative size of the group )

Linguistic proximity

ethnic group

religious diversity;

education and

education relative

Endogamy depends on the size of the group, favorable sex ratios, and spatial segregation. Linguistic ability,

education and religious diversity

reduce endogamy.

to the ethnic group

\section{Age at}

Recently married $(<$

Lievens,

1991

5 years) with Turk or

(1998)

Belgium Moroccan spouse,

arriving 2 years

Same ethnic;

Census district. Group

size; ethnic diversity

index; socioeconomic

diversity

partner

immigration,

generational

status, age at

marriage;

language

Education, region of origin
Higher intermarriage for older immigrants, those arriving younger, and with high education levels

\section{Assortative Matching}

\begin{tabular}{|c|c|c|c|c|c|c|c|}
\hline $\begin{array}{l}\text { Furtado } \\
\text { (2012) }\end{array}$ & $\begin{array}{l}1970 \\
\text { USA }\end{array}$ & $\begin{array}{l}\text { NB married males, } \\
18 \text { to } 65 \text {, with } 2 \text { FB } \\
\text { parents in } 13 \text { ethnic } \\
\text { groups }\end{array}$ & $\begin{array}{l}\text { Married to a person } \\
\text { with one parent } \\
\text { born in same } \mathrm{CO} \text { as } \\
\text { male's fathers } \mathrm{CO}\end{array}$ & County & English ability & Age, & $\begin{array}{l}\text { Evidence of assortative matching on } \\
\text { education. } \\
\text { Some specifications evidence of } \\
\text { cultural adaptability }\end{array}$ \\
\hline
\end{tabular}

\begin{tabular}{|c|c|c|c|c|c|}
\hline $\begin{array}{l}\text { Furtado and } \\
\text { Theodoropoulos } \\
\text { (2011), }\end{array}$ & $\begin{array}{l}2000 \\
\text { USA }\end{array}$ & $\begin{array}{l}\text { Married males } 25 \text { to } \\
65 . \text { Asian, Hispanic } \\
\text { or White ancestry. } \\
\text { FB arriving }<18 \text {. }\end{array}$ & $\begin{array}{l}\text { Both spouses have } \\
\text { the same first } \\
\text { ancestry }\end{array}$ & $\begin{array}{l}\text { MSA, size of ethnic } \\
\text { group }\end{array}$ & Language \\
\hline $\begin{array}{l}\text { Nielsen et Al. } \\
(2006)\end{array}$ & $\begin{array}{l}1999 \\
\text { Denmark }\end{array}$ & $\begin{array}{l}\text { Married } 1^{\text {st }} \text { generation } \\
\text { immigrants from } \\
\text { Pakistan, Turkey and } \\
\text { Yugoslavia. Arrived < } \\
18 \text { (20 years in } \\
\text { Denmark aged } 25-37 \text { ) }\end{array}$ & $\begin{array}{l}\text { Married to equally } \\
\text { educated spouse } \\
\text { (above or below the } \\
\text { median for the } \\
\text { group) }\end{array}$ & None & $\begin{array}{l}\text { Split sample } \\
\text { between those } \\
\text { culturally } \\
\text { assimilated and } \\
\text { at conflict with } \\
\text { parents }\end{array}$ \\
\hline
\end{tabular}

Age, rural, area of residence, veteran status, race
Assortative matching stronger for the NB relative to FB and for immigrants arriving as young children rather than older 


\section{Intermarriage as Assimilation}

\begin{tabular}{|c|c|c|c|c|c|c|c|}
\hline $\begin{array}{l}\text { Meng and } \\
\text { Meurs (2006) }\end{array}$ & $\begin{array}{l}1992 \\
\text { France }\end{array}$ & $\begin{array}{l}\text { Married (CL) } \\
\text { immigrants arriving } \\
\text { single from Spain, } \\
\text { Portugal, Morocco, } \\
\text { Algeria, Turkey, Asia } \\
\text { and Sub-Saharian } \\
\text { Africa }\end{array}$ & $\begin{array}{l}\text { Immigrant married } \\
\text { to a NB }\end{array}$ & $\begin{array}{l}\text { Age-Ethnic-religious } \\
\text { group. Include relative } \\
\text { size and sex ratio } \\
\text { within MMkt? }\end{array}$ & $\begin{array}{l}\text { Years since } \\
\text { migration, } \\
\text { French fluency }\end{array}$ & $\begin{array}{l}\text { Age, schooling, } \\
\text { religion, } \mathrm{CO} \text {, } \\
\text { residence }\end{array}$ & \\
\hline $\begin{array}{l}\text { Meng and } \\
\text { Gregory } \\
\text { (2005) }\end{array}$ & $\begin{array}{l}\text { 1981, } \\
\text { 1986, } \\
1991, \\
1996 \\
\text { Australia }\end{array}$ & All & $\begin{array}{l}\text { Marriage between } \\
\text { NB (includes NZ, } \\
\text { UK, USA, Canada) } \\
\text { and immigrant from } \\
\text { non-English } \\
\text { speaking country }\end{array}$ & $\begin{array}{l}\text { Age-Ethnic-religious } \\
\text { group. Include relative } \\
\text { size and sex ratio } \\
\text { within MMkt }\end{array}$ & $\begin{array}{l}\text { Years since } \\
\text { migration, } \\
\text { English } \\
\text { speaking ability }\end{array}$ & $\begin{array}{l}\text { Age, schooling, } \\
\text { religion, } \mathrm{CO}\end{array}$ & $\begin{array}{l}\text { The young, educated, no religious and } \\
\text { longer in Australia more likely to } \\
\text { intermarriage. } \\
\text { The intermarriage premium seems to } \\
\text { be a reward for assimilation rather } \\
\text { than due to unobserved heterogeneity }\end{array}$ \\
\hline $\begin{array}{l}\text { Kantarevick } \\
\text { (2004); }\end{array}$ & $\begin{array}{l}1970 \\
1980 \\
\text { US }\end{array}$ & $\begin{array}{l}\text { FB married (1st } \\
\text { marriage) males } \\
\text { arrived single with no } \\
\text { English mother } \\
\text { tongue }\end{array}$ & Married to NB & $\begin{array}{l}\text { Ethnic group and } \\
\text { State. Use the fraction } \\
\text { of potential spouses in } \\
\text { the group }\end{array}$ & $\begin{array}{l}\text { Years since } \\
\text { migration, entry } \\
\text { cohort }\end{array}$ & Education, age & $\begin{array}{l}\text { Intermarriage more likely for younger, } \\
\text { better educated and longer in the US. } \\
\text { No evidence of causal relationship of } \\
\text { intermarriage on earnings }\end{array}$ \\
\hline \multicolumn{8}{|c|}{ Timing of First union } \\
\hline $\begin{array}{l}\text { Huschek, } \\
\text { Liefbroer and } \\
\text { de Valk } \\
\text { (2010) }\end{array}$ & $\begin{array}{l}2007, \\
13 \\
\text { European } \\
\text { cities }\end{array}$ & $\begin{array}{l}\text { 2nd Gen Turks, } \\
\text { Moroccan and } \\
\text { Yugoslavians }\end{array}$ & $\begin{array}{l}\text { Timing of first } \\
\text { union }\end{array}$ & \multicolumn{4}{|c|}{$\begin{array}{l}\text { Parental education, family size, co-ethnic contact, age, education, } \\
\text { CO }\end{array}$} \\
\hline $\begin{array}{l}\text { Milewski and } \\
\text { Hamel (2008) }\end{array}$ & $\begin{array}{l}2007 \\
\text { France }\end{array}$ & $\begin{array}{l}\text { 2nd Gen Turkish and } \\
\text { NB reference group }\end{array}$ & $\begin{array}{l}\text { Timing of first } \\
\text { union and } \\
\text { endogamous union. } \\
\text { Also marriage to } \\
\text { older Turkish }\end{array}$ & \multicolumn{3}{|c|}{$\begin{array}{l}\text { Residence, age, religion education, family size parental } \\
\text { education. Also, attended school in Turk and language raised in } \\
\text { (for endogamy) }\end{array}$} & $\begin{array}{l}\text { Faster marriage rates among low } \\
\text { educated Turk women. Low educated } \\
\text { Turk women more likely to marry a } \\
\text { Turkish immigrant, }\end{array}$ \\
\hline \multicolumn{8}{|c|}{$\begin{array}{l}\mathrm{NB}=\text { native-born } \\
\mathrm{FB}=\text { Foreign Born } \\
\mathrm{CO}=\text { Country of Origin }\end{array}$} \\
\hline
\end{tabular}

